\title{
Spatial variability in the mechanical properties of Gilsocarbon
}

DOI:

10.1016/j.carbon.2016.09.051

\section{Document Version}

Accepted author manuscript

Link to publication record in Manchester Research Explorer

\section{Citation for published version (APA):}

Arregui-Mena, J., Bodel, W., Worth, R., Margetts, L., \& Mummery, P. (2016). Spatial variability in the mechanical properties of Gilsocarbon. Carbon, 110, 497-517. https://doi.org/10.1016/j.carbon.2016.09.051

\section{Published in:}

Carbon

\section{Citing this paper}

Please note that where the full-text provided on Manchester Research Explorer is the Author Accepted Manuscript or Proof version this may differ from the final Published version. If citing, it is advised that you check and use the publisher's definitive version.

\section{General rights}

Copyright and moral rights for the publications made accessible in the Research Explorer are retained by the authors and/or other copyright owners and it is a condition of accessing publications that users recognise and abide by the legal requirements associated with these rights.

\section{Takedown policy}

If you believe that this document breaches copyright please refer to the University of Manchester's Takedown Procedures [http://man.ac.uk/04Y6Bo] or contact uml.scholarlycommunications@manchester.ac.uk providing relevant details, so we can investigate your claim.

\section{OPEN ACCESS}




\title{
Spatial variability in the mechanical properties of Gilsocarbon
}

\author{
"José David Arregui-Mena a , William Bodel ${ }^{\mathrm{a}}$, Robert N. Worth ${ }^{\mathrm{a}}$, "Lee Margetts ${ }^{\mathrm{a}}$, Paul M. \\ Mummery ${ }^{\text {a }}$ \\ ${ }^{a}$ School of Mechanical, Aerospace, and Civil Engineering, University of Manchester, Oxford \\ Road, Manchester, M13 9PL, UK
}

\begin{abstract}
The objective of this study is to investigate whether there is significant spatial variability in the mechanical properties of Gilsocarbon nuclear graphite at different sections of the billet; specifically the dynamic Poisson's ratio, dynamic shear modulus, dynamic Young's modulus and density. Similar studies have been done, usually in the context of manufacturing, to assess the quality of graphite components for nuclear reactors. In this new study, the measurements have been carried out at a much higher spatial resolution than previously. A Torness/Heysham B billet was machined into cubes so that measurements could be made across the circumference and height of the billet. ASTM standards were followed to assess the measurements of the samples. The spatial variability of material properties is described and analysed statistically. The study shows that material variability is present at different heights and circumferential locations of the billet. This discovery will have a significant impact on the structural integrity and through life performance predictions made in industry; both in current and future nuclear reactors. The computer modelling of graphite components may predict different outcomes to standard analyses (that use mean values) if this variability is incorporated into the analysis workflow; specifically through stochastic modelling.
\end{abstract}

\section{Introduction}

Gilsocarbon nuclear graphite is used in nuclear power stations, both as a moderator and for structural support [1]. Other applications of graphite in the nuclear industry include neutron

\footnotetext{
*Corresponding authors: arreguimenjd@ornl.gov (José David Arregui Mena), lee.margetts@ manchester.ac.uk (Lee Margetts)
} 
reflectors, fuel-channel sleeves, thermal columns and fuel matrices [2]. The core of an Advanced Gas-cooled Reactor (AGR) comprises columns of various graphite components. There are two main types of graphite brick used; channel bricks that have a round shape with an approximate diameter of $460 \mathrm{~mm}$ and a height between 850-900 $\mathrm{mm}$ depending on the reactor design, and interstitial bricks that are placed in between the channel bricks. Figure 1a shows a channel brick design for the Hartlepool and Heysham power stations and Figure 1b includes the other types of graphite brick that form the AGR graphite core. The number of brick columns that form the core varies between reactors; from 11 to 13 column rings in a particular core. Hollow rings are used as structural components to place the fuel and control rods and solid rings play the role of neutron reflectors (Figure 1c) [3]. A system of radial keys and keyways is used to keep the graphite columns in place and ensure a proper alignment between graphite bricks. The approximate dimensions of an AGR core is 9 metres in diameter by 8 metres deep [4].

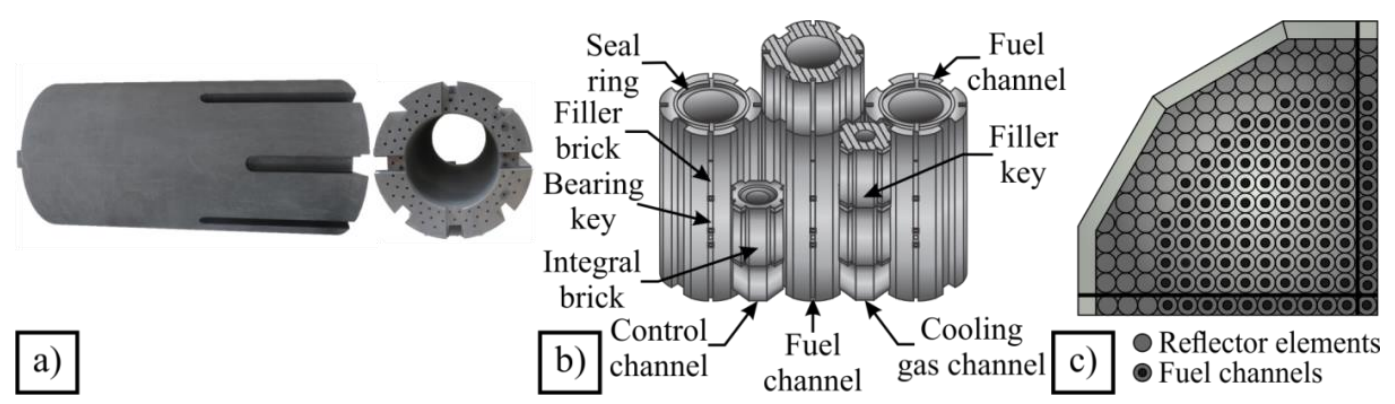

Figure 1. Components of an AGR core: a) Hartlepool/Heysham graphite channel brick, b)

Graphite components in an AGR core (based on [3]) c) Core layout on fourth symmetry (based on [5])

Material variability in nuclear graphite can be a result of multiple factors; such as the manufacturing process, raw materials and natural variability. The graphite core is an important structural component of an AGR, and so it is necessary to assess the variation of mechanical properties across different locations of a nuclear graphite billet from which a moderator brick is machined. Material variability can cause unexpected stresses due to material incompatibilities and flaws in the material. The normal operation of an AGR produces different conditions at the exterior and the interior of a brick channel. The interior of the brick is subjected to higher temperatures and higher fast neutron flux [1]. These conditions lead to different physical and mechanical properties across a billet. A significant difference in material properties at the periphery or exterior of a brick 
channel and at the bore of a channel brick may contribute to the stress concentrations that lead to its failure.

The lifetime of an AGR is assessed by estimating the stresses in graphite components and comparing with strength measurements [6]. Young's modulus and Poisson's ratio are essential mechanical properties to calculate the stresses caused by dimensional changes and thermal strains. Therefore, is it essential to understand the fluctuations of material properties through graphite components.

The purpose of this study is to complement previous studies, providing a new insight into the spatial variation of density, dynamic Poisson's ratio, dynamic shear modulus and dynamic Young's modulus within a single billet. The property values were obtained using the dynamic time of flight method; a technique well known in the nuclear industry that is part of the regular assessment of mechanical properties of nuclear graphite. The median and variance of density and dynamic Young's modulus were compared at the edge and the centre of the billet to determine whether the material properties were statistically different at these two sections. Another motivation for this work is that the material properties obtained can be used to calibrate stochastic finite element models to test the effect of spatial material variability on the structural integrity of graphite components. A study on the effects of material variability in nuclear graphite can be found in reference [7]. For more information about stochastic finite element modelling the reader is referred to [8].

\section{Materials}

\subsection{Gilsocarbon}

In general, nuclear graphite is formed from two constituents: filler and binder. In the case of Gilsocarbon, the filler particles are derived from Gilsonite, using a process which yields spherical coke particles, leading to Gilsocarbon's isotropic properties [9]. The Gilsocarbon manufacturing process is similar to the fabrication of electrode graphite. It starts with calcination, which removes volatiles from the coke and shrinks the particles, preventing significant particle shrinkage and 
associated weakening during the later stages of manufacture. The coke particles are then milled, sized and mixed with a binder pitch. After these stages, the mixture is pressed and moulded; the resulting product is commonly referred to as the green article. The moulding process drastically reduces the preferential alignment of the particles when compared to extrusion [2]. Following the formation of the green article, a baking step removes some of the volatiles from the pitch binder and provides structural integrity to the green article. The baked article is then impregnated with more pitch and baked again, reducing the amount of porosity and increasing the density, Young's modulus and strength [9]. The next stage is graphitisation. The impregnated baked articles are placed into a furnace that raises the temperature up to $3000^{\circ} \mathrm{C}$, releasing some of the remaining volatile material from the billet and promoting its graphitisation [2]. The impregnation process is repeated if required. The final step is the machining of the different graphite components.

Most of the material property data that exists for Gilsocarbon arises from measurements taken during manufacture [4]. A batch of around one hundred channel bricks or one "heat", are graphitised inside an Acheson furnace; a few of these bricks are tested to verify the quality of the bricks. These records, known as heat certificates, are one of the largest sources of property data available for AGR graphite moderator bricks [10]. A statistical analysis of the heat certificates can be found elsewhere [11].

Other sources of material property data include Preston [10, 12], Novovic and Bowen [13] and Mostafavi and Marrow [14]. In Preston's study, a block of Gilsocarbon (approximately $470 \mathrm{~mm}$ in diameter and $570 \mathrm{~mm}$ in length) was machined into 343 samples of different sizes and shapes to measure density, electrical resistivity, coefficient of thermal expansion, four point bending strength, compressive strength, Young's modulus, tensile strength, thermal conductivity, open pore volume, closed pore volume and Poisson's ratio. Novovic and Bowen [13] investigated the influence of specimen sizes on measurements of compressive strength. A similar study has been carried out by Mostafavi and Marrow [14]; using uniaxial tests and digital image correlation to measure the strength of graphite. One of their findings was that strength varies across the billet.

Although Preston's data is the largest compendium of material properties collected for a single billet, the experimental work did not evaluate mechanical properties in all directions. For example, 
the dynamic Young's modulus specimens had a long thin shape, only suitable for measurements in one direction. Another issue is that there is little spatial data across the billet. Only 6 samples were used to determine Poisson's ratio. Furthermore, the specimens were sourced at 3 different heights of approximately half of a billet, insufficient sampling to understand of the spatial variability of elastic properties.

In contrast to these studies (and heat certificate data), our investigation was specifically designed to determine the spatial variability of material properties at different heights and at different locations around the circumference of a billet; requiring a larger number of samples and better spread of the locations inspected.

\subsection{Sample preparation}

Ideally, the entire billet should be reduced into smaller test specimens to assess the mechanical properties of the billet. Time and resource limitations make complete billet testing impractical, and so to reduce the number of samples to be examined, a sampling plan was adopted. Two sampling procedures are often implemented when spatial data is considered to be relevant; random sampling and systematic sampling.

The first approach takes a number of samples chosen randomly from any location in space. The sample is treated as a random variable that is independent of other samples and has the same chance

of being selected. A randomised sampling cutting plan would reduce the effect of dependency between samples, although randomisation does not remove the effect of spatial correlation between material property values [15].

The second approach is to create a systematic grid across the medium and take samples at each location of the grid. In the systematic grid approach, the samples are taken at a consistent or similar distance to each other called the lag [15]. Systematic sampling usually offers better population parameter estimates than the random sampling techniques [16]. 
The data in our study were collected using a systematic grid approach. This was for two reasons; firstly we wish to systematically assess the spatial variability of material properties and secondly, from a practical point of view, random sampling can be difficult to machine. Sampling schemes in the context of nuclear graphite are further discussed in references $[17,18]$.

The billet was machined at the facilities of Erodex (UK) Ltd. The machining process started with the cutting of 11 sections, where 3 discs and 8 outside slabs were obtained. All of the discs and slabs were temporarily labelled with the original position within the billet. The slabs and discs were then machined into 508 cubes, 36 rectangular blocks and 6 slices. Figure 2 illustrates the different stages of the cutting of the billet. The dimensions, description and specifications of each type of specimen are listed in Table 1. The size and shape of the cubic samples enable measurements in the three orthogonal directions of the cube and are appropriate for future mechanical tests and measurements. Time of flight measurement on thin samples using this apparatus is complex, owing to the more intensive signal analysis required. Measuring time of flight on larger specimens results in proportionally smaller error in the time of flight data. Larger samples clearly result in fewer test specimens from a limited amount of billet materials. For $40 \times 40 \times 40 \mathrm{~mm}$ samples, 76 specimens can be cut from a disc cross-section of the billet, and 18 such discs can be cut from the total billet. For $50 \times 50 \times 50 \mathrm{~mm}$ samples, these numbers drop to 52 and 15 respectively. Furthermore, the size of the samples was chosen to ensure that the specimens retain the mechanical properties and characteristics of the bulk material.

Table 1. Type of specimen and their general description

\begin{tabular}{|c|c|c|l|}
\hline Type of specimen & $\begin{array}{c}\text { Number of } \\
\text { specimens }\end{array}$ & $\begin{array}{c}\text { Dimensions } \\
(\mathrm{mm})\end{array}$ & $\begin{array}{c}\text { Type of measurement or purpose of the } \\
\text { specimen }\end{array}$ \\
\hline Cube & 508 & $40 \times 40 \times 40$ & $\begin{array}{c}\text { Density, dynamic Young's modulus, dynamic } \\
\text { Poisson's ratio, dynamic shear modulus }\end{array}$ \\
\hline Rectangular prism & 32 & $40 \times 30 \times 20$ & Microstructural evaluation \\
\hline Slices & 6 & $40 \times 30 \times 10$ & N
\end{tabular}




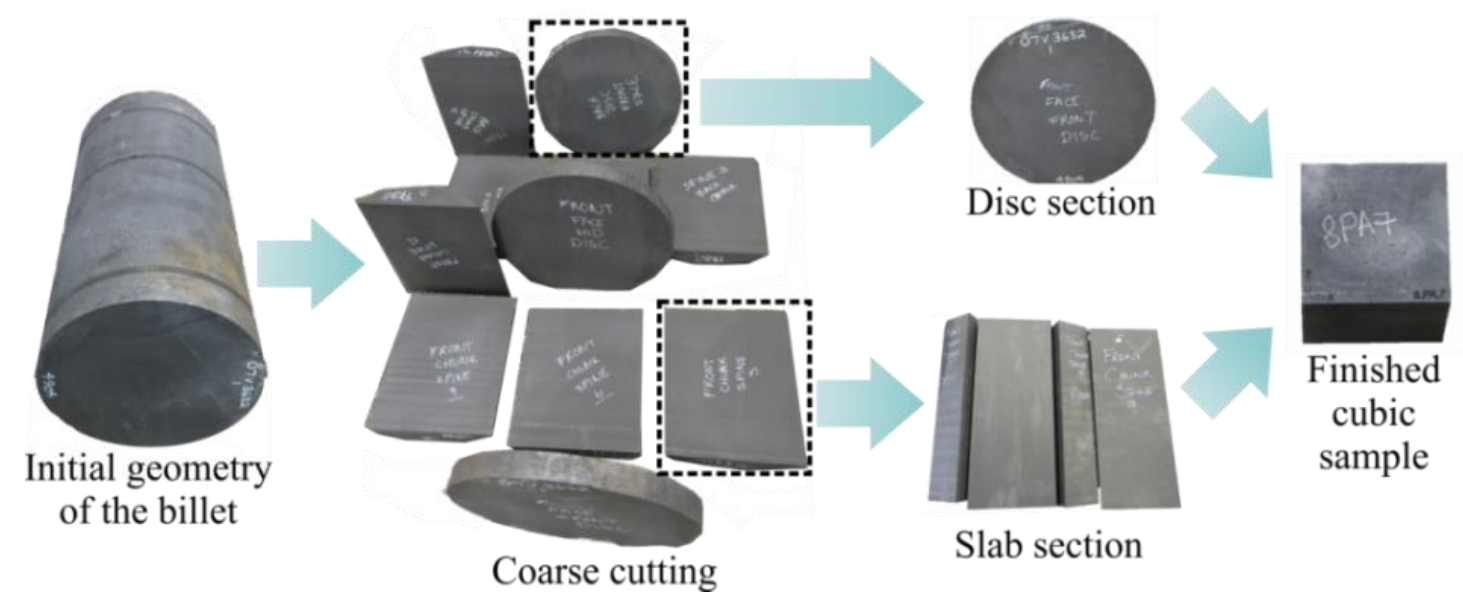

Figure 2. Machining process for cubic samples

Figure 3a shows an isometric view of the specimen locations, and names for the plates and spine sections. The usual lag or distance between specimens is $42 \mathrm{~mm}$ between the centroids of the cubic samples and there is a distance of $2 \mathrm{~mm}$ between the edges of most of the specimens due to wastage during machining. Cubes that are shared between the plates and spines are displaced in the $\mathrm{x}$ or $\mathrm{z}$ directions by a distance of $8 \mathrm{~mm}$, as specified in Figure 3b. This separation between these specimens was necessary to maintain the traceability of the plate samples and for the spine sections to be as close as possible to the edges of the brick.

Due to problems during the machining process, 36 of the cubic samples located at the bottom of spine 9 have a shorter side of $38.735 \mathrm{~mm}$ in the $\mathrm{z}$ direction. Even though the central region of the billet would be removed to create a fuel channel, the central region was included in the sampling process (Figure 3c).

The traceability of the original position of each sample is fundamental for this study, thus 4 permanent labels noting the directions were made with a laser marker. These labels help to identify the location and orientation of each cube. 


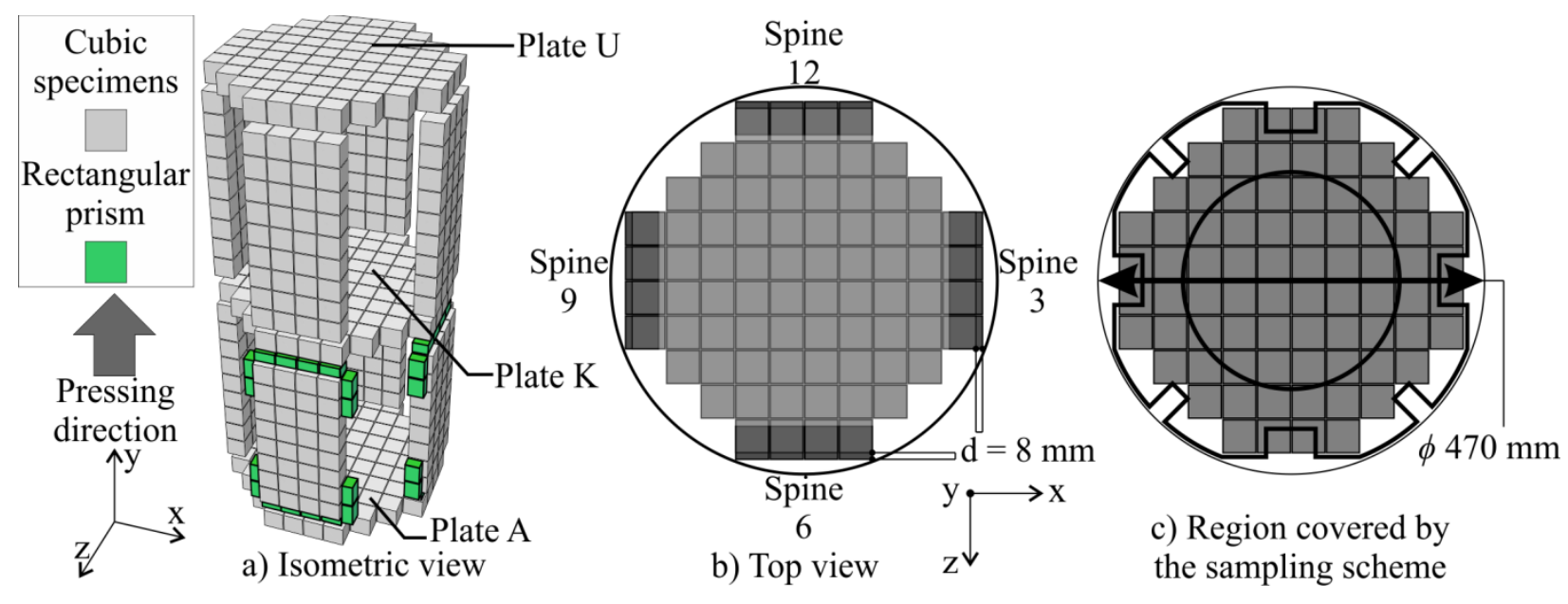

Figure 3. Section label system and location of all the specimens. a) Isometric view. b) Top view.

c) Region covered by the sampling scheme

\subsection{Data Collection}

A total of 19,676 measurements were collected for this paper, thus the collection and organisation of the data is key to generate a reliable database. The data was manually recorded in a Microsoft Excel (2010) spreadsheet.

\section{Methods}

\subsection{Laser confocal microscopy}

The microstructure of 6 samples of Gilsocarbon was examined using a laser confocal scanning digital microscope, Olympus Lext OLS4100. The slices were hand-polished with different SiC abrasive papers to produce an appropriate surface for the image acquisition. The size of the filler particles was measured with the aid of the laser confocal software application version 3.1.4.1 to check that the specimen size complies with the requirements of the American Society for Testing and Materials (ASTM) Standard C559-90 [19]. Figure 4 illustrates the typical microstructure found in the tested samples. 


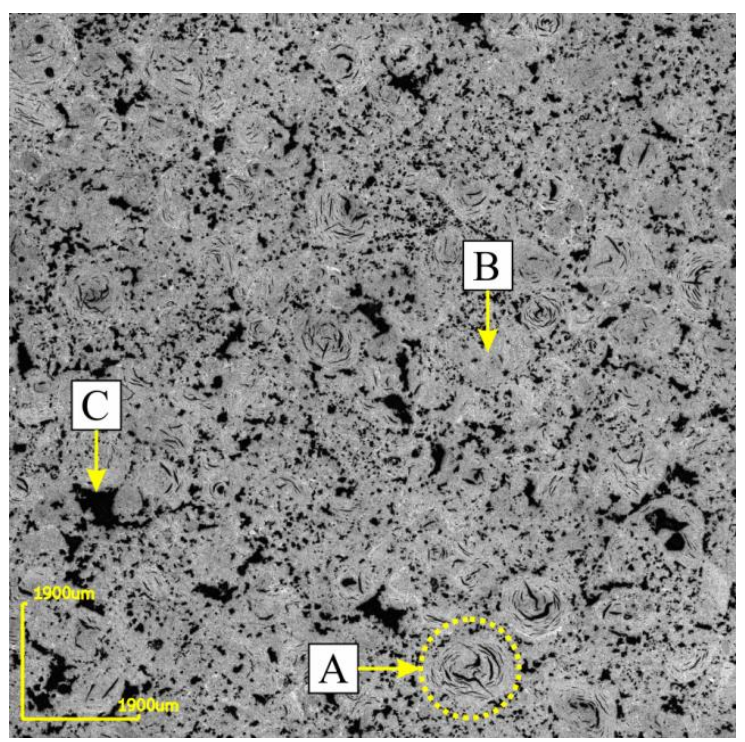

Figure 4. Optical micrograph of Gilsocarbon nuclear graphite: A - Spherical filler particle, B Binder matrix, C - Porosity

\subsection{Density measurements}

Bulk density measurements for all the samples were carried out according to ASTM Standard C559-90 [19]. The density of the samples was calculated using the dimensions and mass, measured in air at room temperature and pressure. The dimensions of the cubic samples were measured at 27 different positions, with 9 measurements in each orthogonal direction, using a digital micrometer with a resolution of $0.001 \mathrm{~mm}$. Mass measurements were carried out with a digital balance with a resolution of $0.01 \mathrm{~g}$. The measurements were repeated three times for each sample and the average value was recorded.

\subsection{Dynamic Poisson's ratio, dynamic shear modulus and dynamic Young's modulus measurements}

The time of flight technique was selected to measure the dynamic Poisson's ratio, shear modulus and Young's modulus of the specimens. This technique offers the advantage of inducing negligible stresses in the sample, such that the stress does not exceed the elastic limit of the material. Furthermore, the non-destructive nature of this technique allows multiple measurements of a specimen to be taken. Importantly, this method has already been used in the nuclear industry to 
determine the elastic properties of nuclear graphite [20-25], and the use of these techniques here allows for comparison with historical data.

Poisson's ratio was determined, following the British Standard for advanced technical ceramics BS EN843-2:2006 [26], using equation 1:

$$
v=0.5 \frac{V_{L}^{2}-2 V_{T}^{2}}{V_{L}^{2}-V_{T}^{2}}
$$

where $v$ is the Poisson's ratio, $V_{L}$ is the velocity of the longitudinal pulse derived from the time of flight and length of the sample, and $V_{T}$ is the velocity of the transverse pulse determined in the same fashion. These velocities were measured independently. As this material is isotropic, only one measurement of $\mathrm{V}_{\mathrm{T}}$ was taken at each position. Measurements of dynamic Poisson's ratio and dynamic shear modulus were carried out for the 256 specimens of plate $\mathrm{A}, \mathrm{K}$ and $\mathrm{U}$.

The dynamic shear modulus was also obtained according to the aforementioned British standard for advanced ceramics [26]. Equation 2 was used:

$$
G=\rho V_{T}^{2}
$$

where $G$ is the dynamic shear modulus and $\rho$ is the bulk density of the graphite specimen. The measurements for dynamic shear modulus were obtained for the 256 specimens of the plate sections.

The ASTM standard C769-09 was followed for dynamic Young's modulus, using Equation 3:

$$
E=\rho V_{L}^{2} \frac{(1+v)(1-2 v)}{1-v}
$$

where $E$ is the dynamic Young's modulus. In this test, a coupling agent was used to reduce the effects of roughness and natural defects of the specimen's surfaces. The flight times for all 
measurement techniques previously described were measured at the $10 \%$ rise point of the first peak.

The Poisson's ratio (v) values used to calculate the dynamic Young's modulus in the $\mathrm{x}$ and $\mathrm{z}$ directions were 0.22 . The value 0.21 was used in the $y$ direction. These values were the averages calculated for plates $\mathrm{A}, \mathrm{K}$ and $\mathrm{U}$.

\section{Results}

\subsection{Density measurements}

Density measurements are summarised in the form of a bar chart in Figure 5a. The bar chart contains all of the density experimental measurements; a different colour is assigned for the plate and disc sections. The box plots (Figure 5b) summarise the range, average and dispersion for the whole data sets and individual regions. Higher density values are found in spine 3 and spine 12, and the lowest ones are found in plates $\mathrm{K}$ and $\mathrm{U}$. Table 2 summarises the average and standard deviation for each section of the billet. The standard deviation of density is between 5.87 and 9.09

$\mathrm{kg} / \mathrm{m}^{3}$, approximately only $30 \%$ of the difference between the maximum and minimum average of the different sections. The averages of the different regions can fluctuate from $1824.13 \mathrm{~kg} / \mathrm{m}^{3}$ to $1854.25 \mathrm{~kg} / \mathrm{m}^{3}$. 


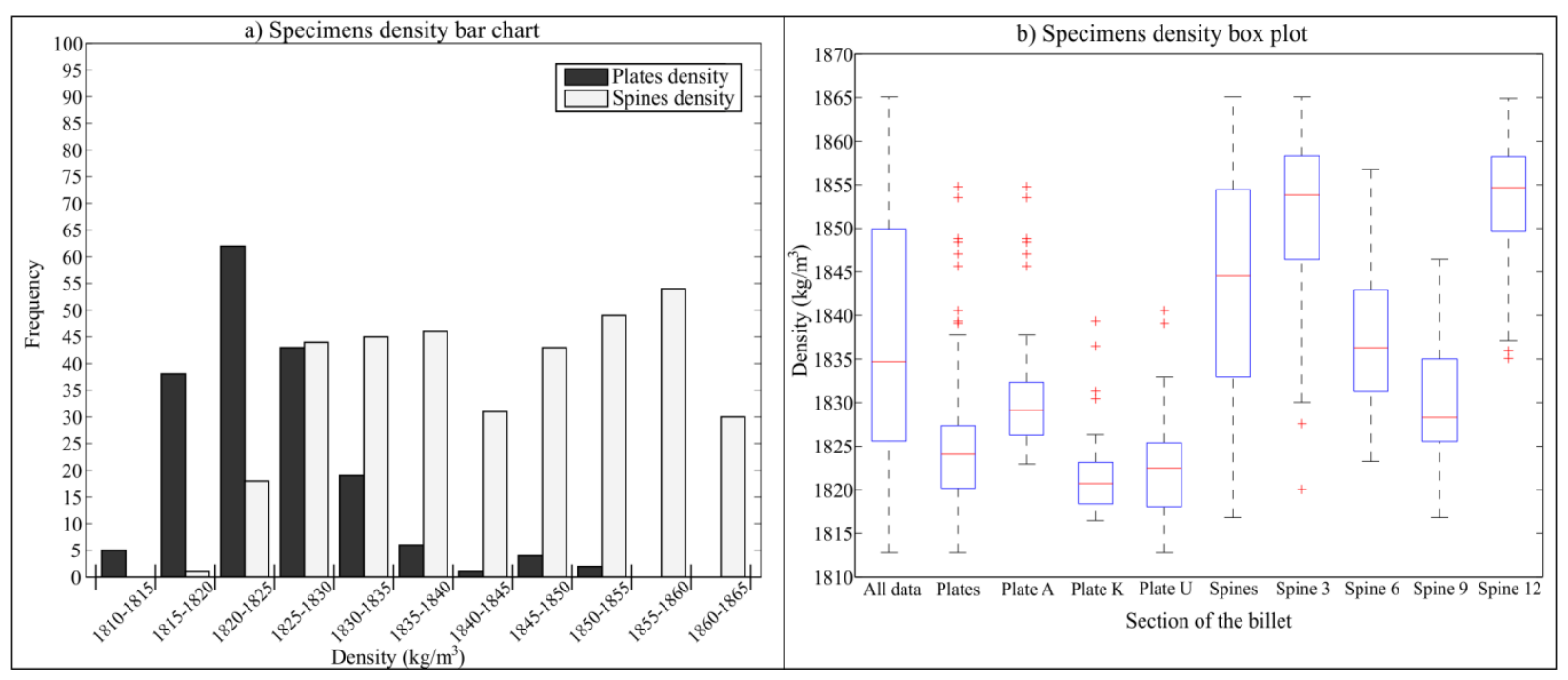

Figure 5. Bar chart and box plots for the Gilsocarbon density measurements. a) Density bar chart for all the specimens. b) Box plots for all the specimens. The whiskers represent the maximum and minimum values, the crosses indicate the outliers, the line is the mean and the boxes represent the lower and upper quartile of the density values. The outlier values are the values that are larger than $\mathrm{q}_{3}+\mathrm{w}\left(\mathrm{q}_{3}-\mathrm{q}_{1}\right)$ or smaller than $\mathrm{q}_{1}-\mathrm{w}\left(\mathrm{q}_{3}-\mathrm{q}_{1}\right)$, where $\mathrm{q}_{1}$ and $\mathrm{q}_{3}$ are the $25^{\text {th }}$ and $75^{\text {th }}$ percentiles and $\mathrm{w}$ is equal to 1.5 .

Table 2. Density averages and standard deviations for each section of the billet

\begin{tabular}{|c|c|c|}
\hline Section & $\begin{array}{c}\text { Density average } \\
\text { value }\left(\mathrm{kg} / \mathrm{m}^{3}\right)\end{array}$ & $\begin{array}{c}\text { Density standard } \\
\text { deviation }\left(\mathrm{kg} / \mathrm{m}^{3}\right)\end{array}$ \\
\hline All data & 1837.32 & 13.91 \\
\hline Plate A & 1832.78 & 8.88 \\
\hline Plate K & 1825.05 & 9.09 \\
\hline Plate U & 1824.13 & 6.80 \\
\hline Spine 3 & 1854.25 & 6.66 \\
\hline Spine 6 & 1838.35 & 8.63 \\
\hline Spine 9 & 1831.21 & 6.43 \\
\hline Spine 12 & 1854.14 & 5.87 \\
\hline
\end{tabular}

Further analysis of the density data is presented using maps that show the approximate location of the sample and the density values. Figures $6 a-6 c$ present the density values for the plate sections 
and $7 \mathrm{a}-7 \mathrm{~d}$ for the spine sections. The density map for Plate A (Figure 6a) presents the highest spatial variation of density values, and the highest values of density for a plate section. Figures $7 \mathrm{a}$ to $7 \mathrm{~d}$ show that density variations are present at different heights of the billet. The variations of spatial variability of density through the height of the billet are shown in Figure 8. 


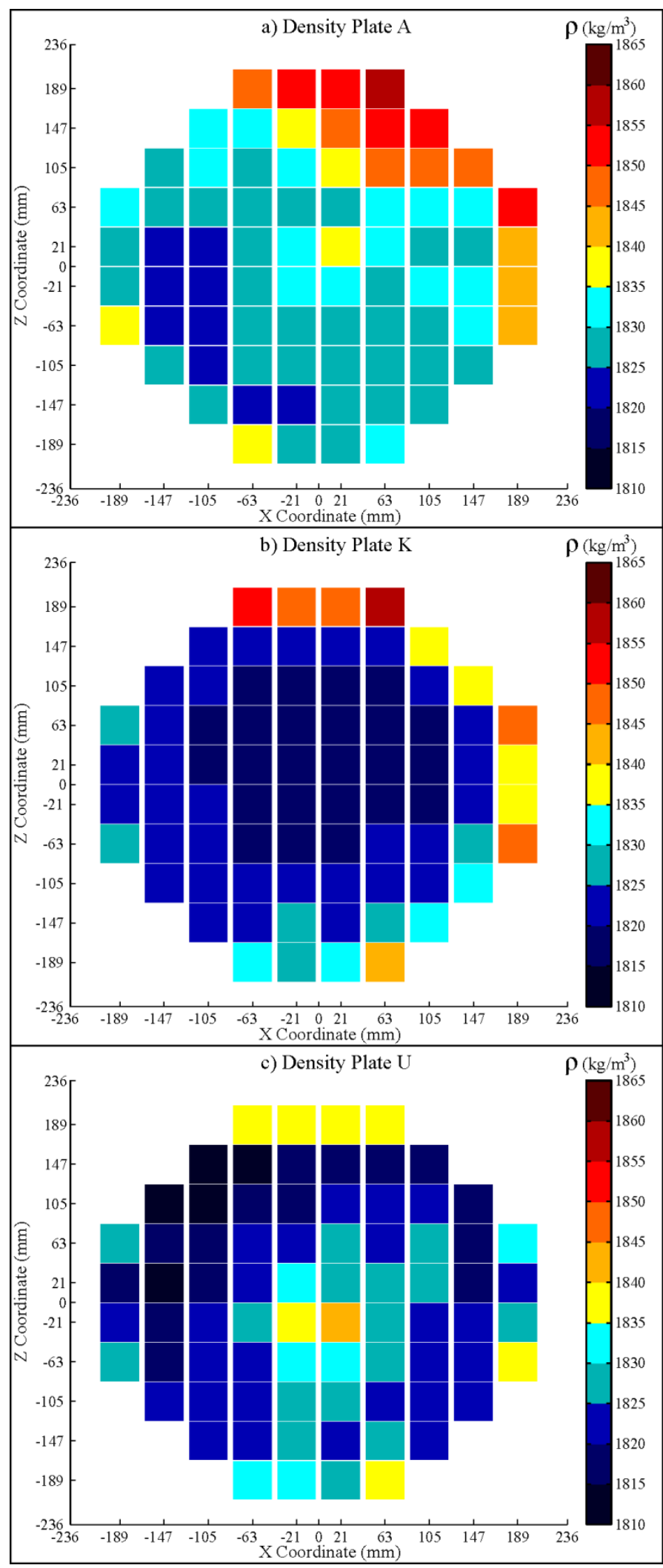

Figure 6. Map of the density distribution for the plate sections. a) Density values for plate A, b) Density values for plate K, c) Density values for plate U. 


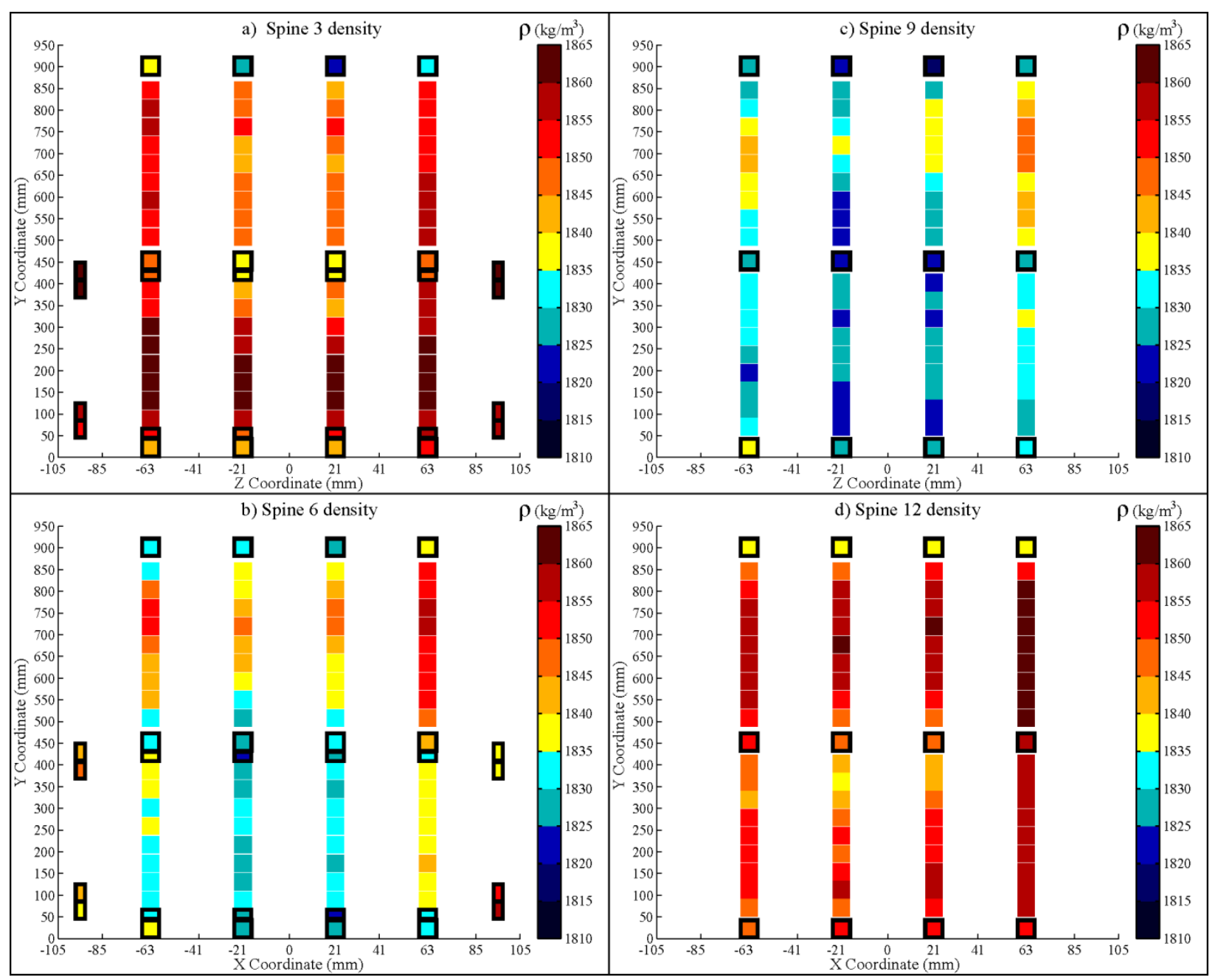

Figure 7. Map of the density $(\rho)$ distribution for the spine sections. The cubic samples that belong to both the spines and plates have a black outline. The rectangular prism samples appear as smaller cubes with a black outline. a) Spine 3 density values, b) Spine 6 density values, c) Spine 9 density values, d) Spine 12 density values. 


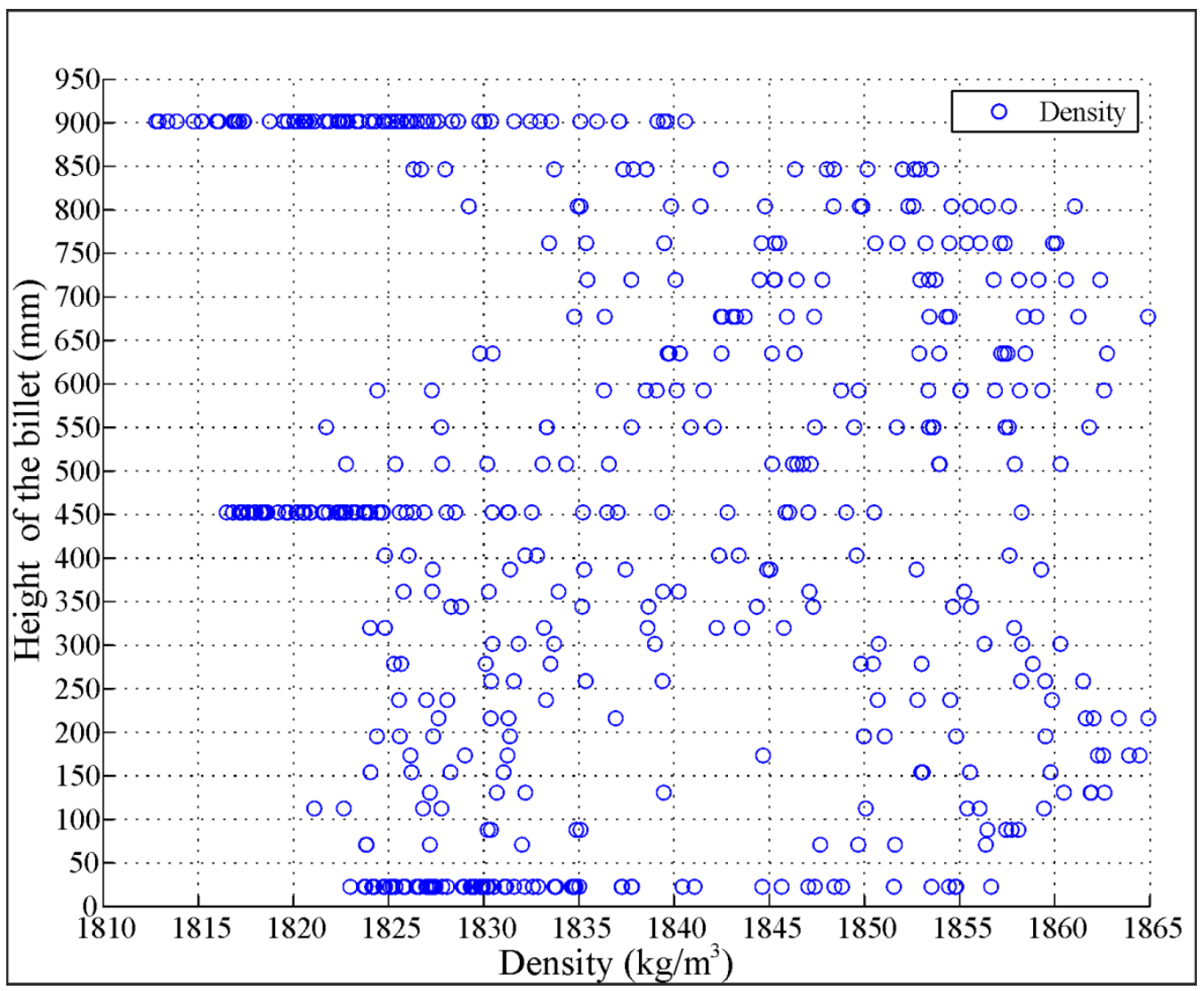

Figure 8 . Variation of density through the height of the billet

\subsection{Dynamic Poisson's ratio measurements}

Figure 9 shows the values of dynamic Poisson's ratio as a function of density and linear regression models for each orthogonal direction. The dynamic Poisson's ratio values are between 0.2054 and 0.2310 showing some degree of variability through the plates. Lower values of dynamic Poisson's ratio were found in the y direction as can been seen from Figure 9 and Table 3. Moreover, the values in the $\mathrm{x}$ and $\mathrm{z}$ direction are fairly similar as can been seen from Figure 9. Lower dynamic Poisson's ratio data points are found in samples with less density, whilst denser samples show higher values.

To extend the analysis of spatial variability of material properties in plates $\mathrm{A}, \mathrm{K}$ and $\mathrm{U}$ maps were created to show the values of dynamic Poisson's ratio (Figure 10a-10f and Figure 11a-11c). 
Average values in the $\mathrm{x}$ and $\mathrm{z}$ directions for dynamic Poisson's ratio are in the range represented by the values between 0.213 and 0.222 in the plots of Figures 10 and 11. Figures 10a, 10c, 10d and $10 \mathrm{e}$ show a predominance of this colour around the plates, whereas Figure 10b and 10d contain regions of lower values. Regarding plate $\mathrm{U}$, the dynamic Poisson's ratio in the $\mathrm{x}$ and $\mathrm{z}$ directions are between the average and higher values (Figure 11a and 11c). A similar trend to plate A and $\mathrm{K}$ was found for the dynamic Poisson's ratio in the y direction, with data points that are around the average, with many values in the lower range.

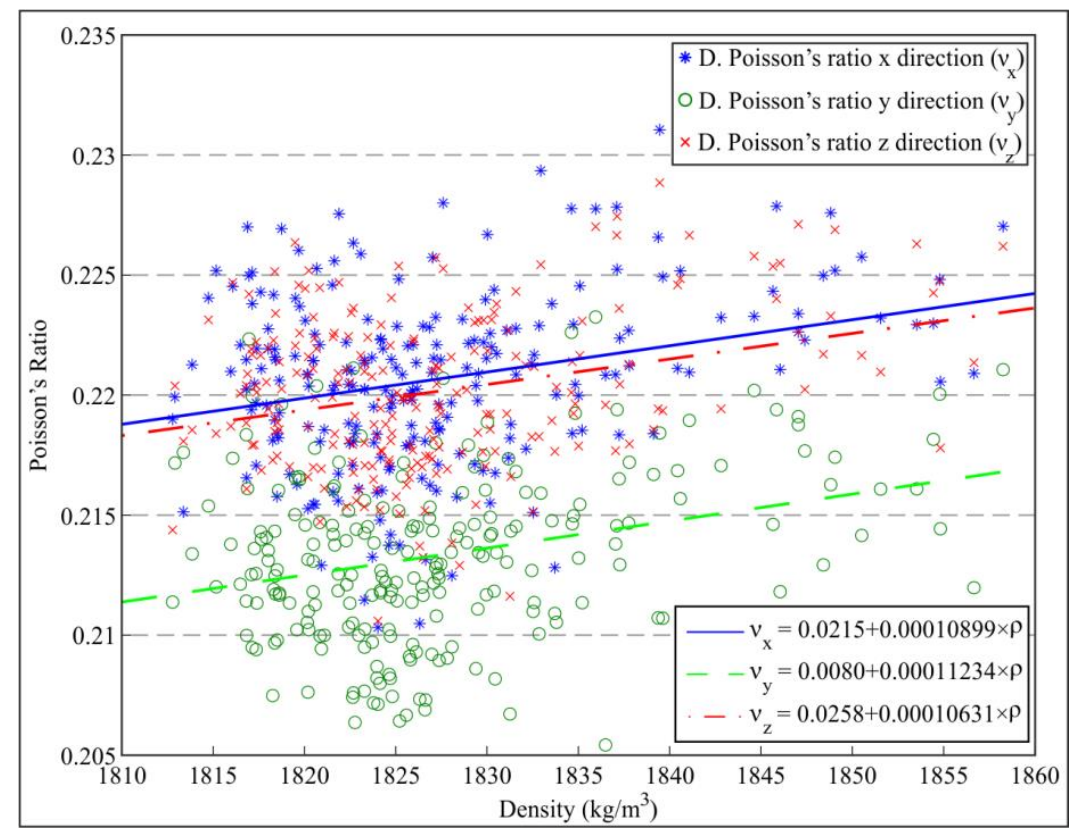

Figure 9. Dynamic Poisson's ratio versus density for plate sections

Table 3. Descriptive statistics of dynamic Poisson's ratio data for plates A, K and U

\begin{tabular}{|c|c|c|c|}
\hline Statistic & $\begin{array}{c}\text { Dynamic } \\
\text { Poisson's } \\
\text { ratio - x }\end{array}$ & $\begin{array}{c}\text { Dynamic } \\
\text { Poisson's } \\
\text { ratio - y }\end{array}$ & $\begin{array}{c}\text { Dynamic } \\
\text { Poisson's } \\
\text { ratio - z }\end{array}$ \\
\hline Mean & 0.2206 & 0.2133 & 0.2201 \\
\hline Standard Error & 0.0002 & 0.0002 & 0.0002 \\
\hline Median & 0.2208 & 0.2131 & 0.2199 \\
\hline Standard Deviation & 0.0036 & 0.0035 & 0.0032 \\
\hline Minimum & 0.2103 & 0.2054 & 0.2105 \\
\hline Maximum & 0.2310 & 0.2232 & 0.2288 \\
\hline
\end{tabular}




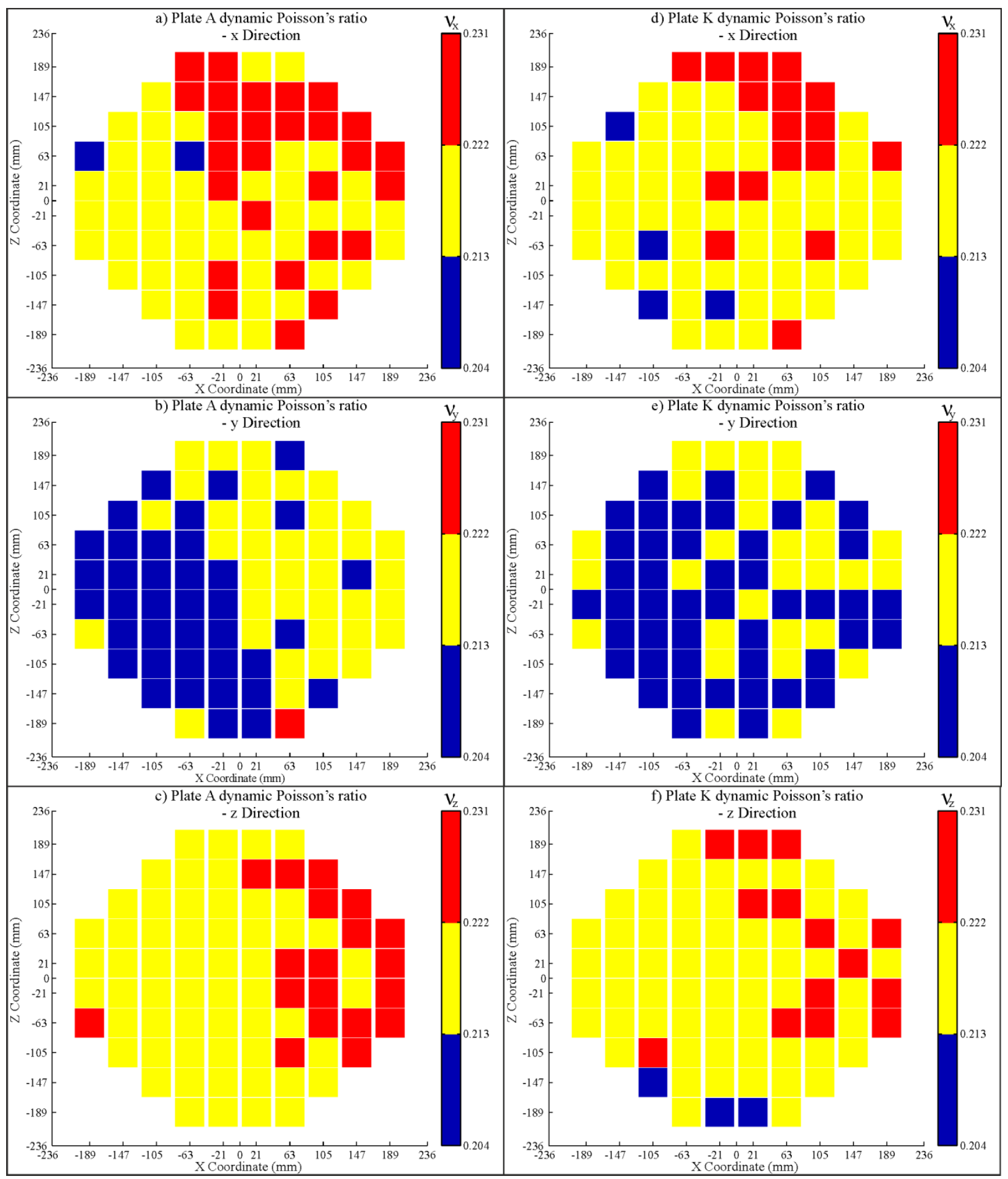

Figure 10. Map for the dynamic Poisson's ratio (DPR) distribution for plate A and K sections.

a) Plate A DPR in the $\mathrm{x}$ direction, b) Plate A DPR in y direction, c) Plate A DPR in z direction, d) Plate K DPR in $x$ direction, e) Plate K DPR in y direction, f) Plate K DPR in z direction 


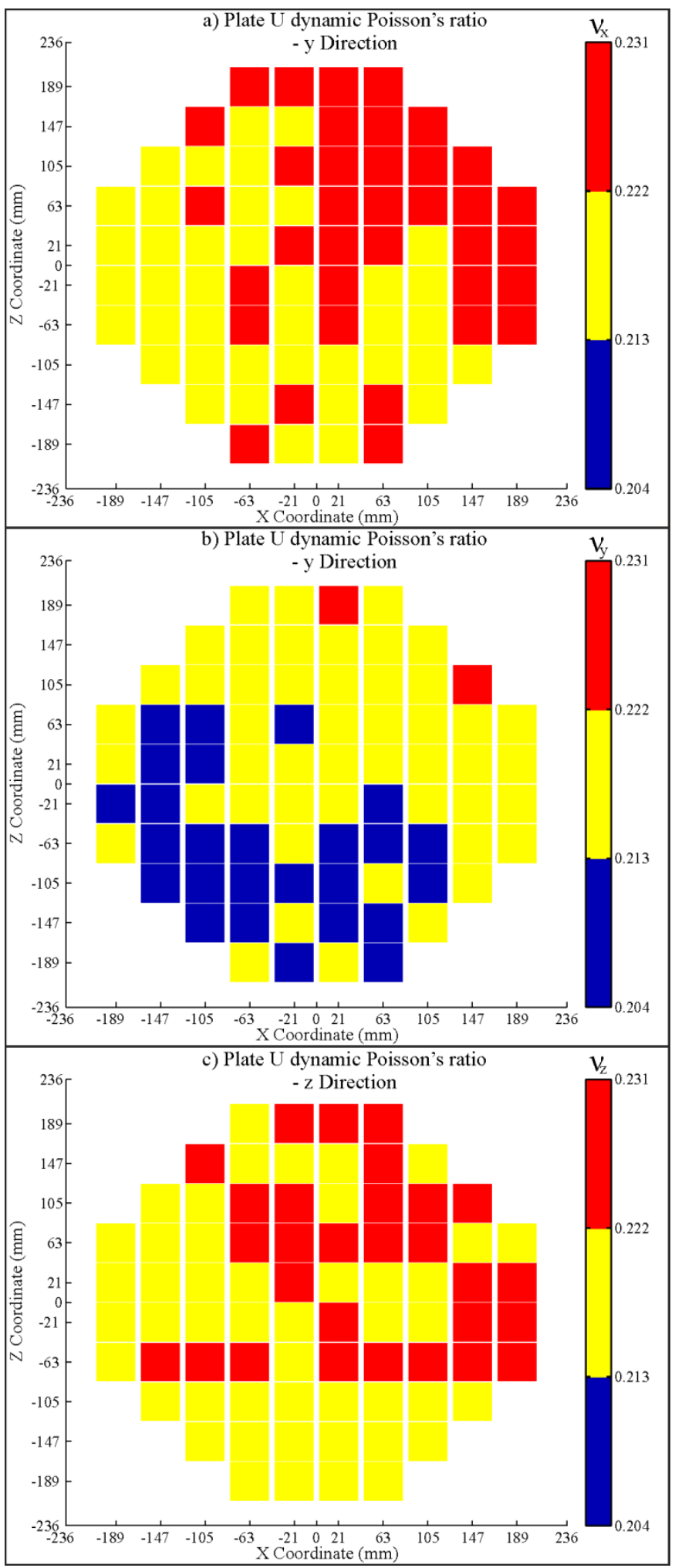

Figure 11. Map for the dynamic Poisson's ratio (DPR) distribution for plate U. a) Plate U DPR in the $\mathrm{x}$ direction, $\mathrm{b}$ ) Plate U DPR in y direction, c) Plate U DPR in $\mathrm{z}$ direction 


\subsection{Dynamic shear modulus measurements}

Figure 12 presents the relationship between density and dynamic shear modulus and linear regression models for each orthogonal direction. A linear relationship was found between density and the dynamic shear modulus. Table 4 provides the summary statistics for the dynamic shear modulus values. This table also compares the experimental data on dynamic shear modulus showing that the variation of this particular material property is high through the plates. A variation of up to $13 \%$ can be found between dynamic shear modulus values. Figure 12 shows that the dynamic shear modulus values are similar through the 3 orthogonal directions.

Table 4. Descriptive statistics of dynamic shear modulus data for plate $\mathrm{A}, \mathrm{K}$ and $\mathrm{U}$

\begin{tabular}{|c|c|c|c|}
\hline Statistic & $\mathrm{x}-$ Direction & $\mathrm{y}-$ Direction & $\mathrm{z}$ - Direction \\
\hline Mean $(\mathrm{GPa})$ & 5.1356 & 5.0437 & 5.1219 \\
\hline Standard Error $(\mathrm{GPa})$ & 0.0085 & 0.0088 & 0.0089 \\
\hline Median $(\mathrm{GPa})$ & 5.1374 & 5.0349 & 5.1258 \\
\hline Standard Deviation $(\mathrm{GPa})$ & 0.1295 & 0.1343 & 0.1344 \\
\hline Minimum $(\mathrm{GPa})$ & 4.8887 & 4.7947 & 4.8840 \\
\hline Maximum $(\mathrm{GPa})$ & 5.5110 & 5.4281 & 5.4946 \\
\hline
\end{tabular}




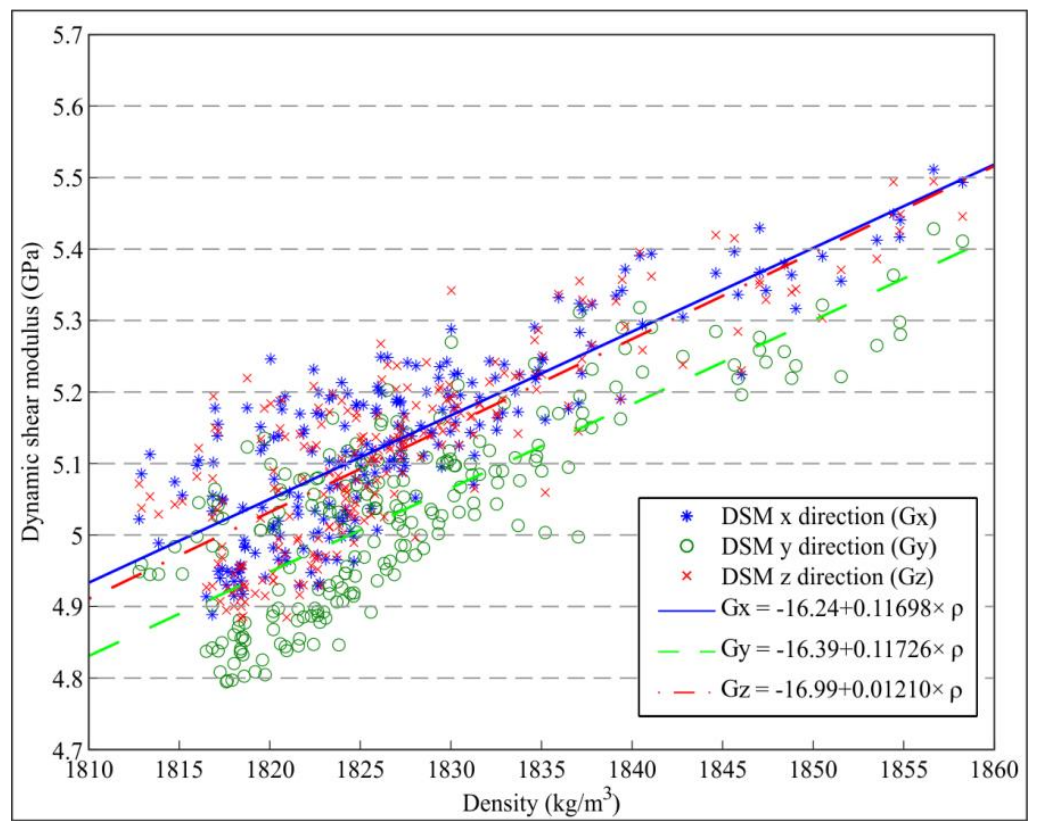

Figure 12. Dynamic shear modulus versus density for plates $\mathrm{A}, \mathrm{K}$ and $\mathrm{U}$ and linear regression models

\subsection{Dynamic Young's modulus measurements}

The Poisson's ratio value used to calculate the dynamic Young's modulus in the $\mathrm{x}$ and $\mathrm{z}$ direction was 0.22 ; a value of 0.21 was used in the $y$ direction. These values were the mean dynamic Poisson's ratios calculated for plates A, K and U. To test the quality of the approximations using the average Poisson coefficients the dynamic Poisson's ratios for each sample were used to compute the dynamic Young's modulus. The maximum percentage difference between the calculations was $1.35 \%$. Therefore, the authors considered that the approximations using the average Poisson's coefficients were accurate enough.

When the density average $\left(1837.32 \mathrm{~kg} / \mathrm{m}^{3}\right)$ is used for the calculations of Young's modulus the standard deviations for each orthogonal direction are smaller than with the computed values for each sample. The averages calculated with the average density are very similar to the data points computed with the real density values. The averages and standard deviation values for dynamic Young's modulus calculated with the average density are 12.778 and 0.376 for the $\mathrm{x}$ direction, 12.556 and 0.142 for the $y$ direction and 12.741 and 0.376 for the $\mathrm{z}$ direction. 
The data for dynamic Young's modulus is presented in Figure 13. This figure is divided into a bar chart (Figure 13a) and a box plot (Figure 13b). Figure 13a differentiates the location of the data by assigning a colour to the plate and spine measurements. Most of the outliers of the boxplot for Plate A and K (Figure 13b) correspond to the density outliers of Figure 5. Averages and standard deviations of the dynamic Young's modulus are presented in Table 5.
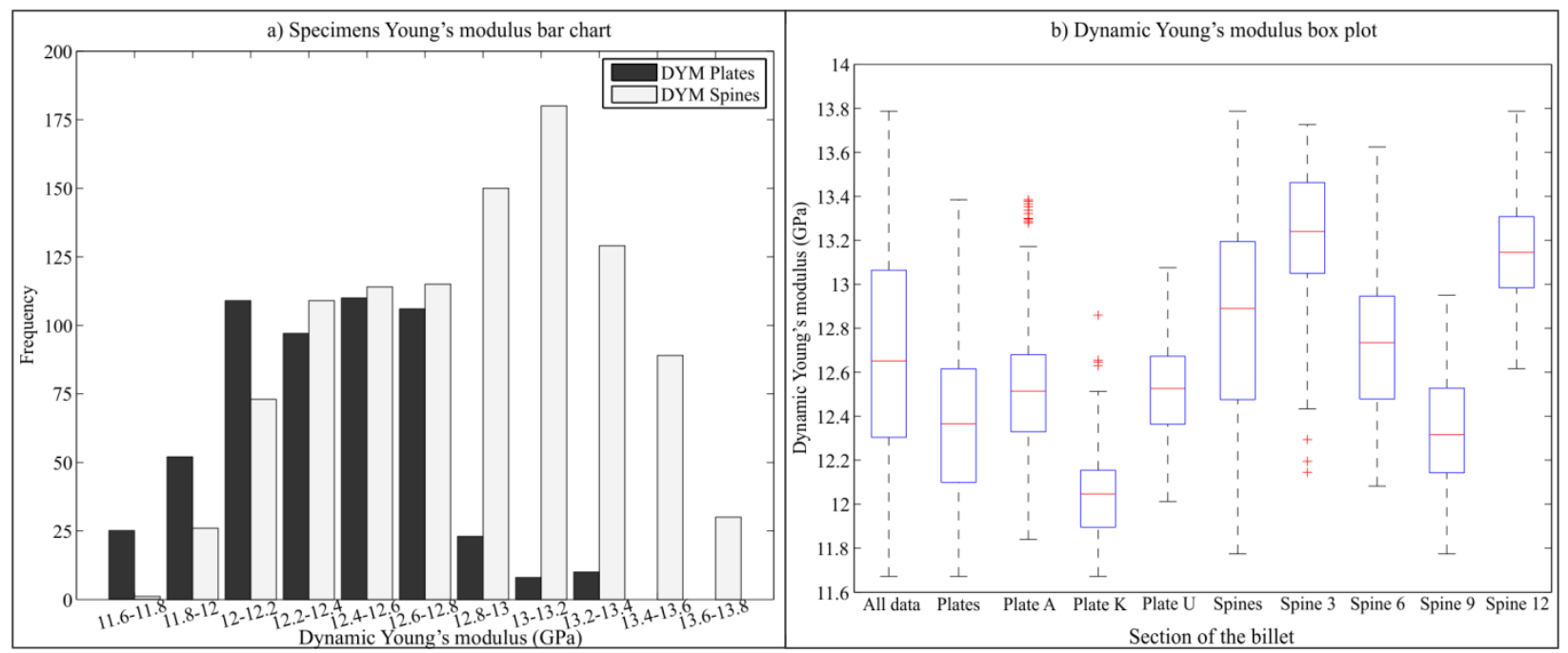

Figure 13. Dynamic Young's modulus bar chart and box plot. a) Dynamic Young's modulus bar chart b) Dynamic Young's modulus box plot. The whiskers represent the maximum and minimum values, the crosses indicate the outliers, the line is the mean and the boxes represent the lower and upper quartile of the density values. The outlier values are the values that are larger than $\mathrm{q}_{3}+\mathrm{w}\left(\mathrm{q}_{3}-\mathrm{q}_{1}\right)$ or smaller than $\mathrm{q}_{1}-\mathrm{w}\left(\mathrm{q}_{3}-\mathrm{q}_{1}\right)$, where $\mathrm{q}_{1}$ and $\mathrm{q}_{3}$ are the $25^{\text {th }}$ and $75^{\text {th }}$ percentiles and $\mathrm{w}$ is equal to 1.5 . 
Table 5. Dynamic Young's modulus averages and standard deviations for each section of the billet

\begin{tabular}{|c|c|c|c|c|c|c|c|c|}
\hline & \multicolumn{2}{|c|}{ All directions } & \multicolumn{2}{c|}{ DYM $_{\mathrm{x}}$} & \multicolumn{2}{c|}{ DYM $_{\mathrm{y}}$} & \multicolumn{2}{c|}{ DYM $_{\mathrm{z}}$} \\
\cline { 2 - 10 } & $\begin{array}{c}\text { Average } \\
(\mathrm{GPa})\end{array}$ & $\begin{array}{c}\text { Stand. } \\
\text { Dev. } \\
(\mathrm{GPa})\end{array}$ & $\begin{array}{c}\text { Average } \\
(\mathrm{GPa})\end{array}$ & $\begin{array}{c}\text { Stand. } \\
\text { Dev. } \\
(\mathrm{GPa})\end{array}$ & $\begin{array}{c}\text { Average } \\
(\mathrm{GPa})\end{array}$ & $\begin{array}{c}\text { Stand. } \\
(\mathrm{GPa})\end{array}$ & $\begin{array}{c}\text { Average } \\
(\mathrm{GPa})\end{array}$ & $\begin{array}{c}\text { Dev. } \\
(\mathrm{GPa})\end{array}$ \\
\hline All data & 12.680 & 0.478 & 12.776 & 0.459 & 12.559 & 0.495 & 12.741 & 0.461 \\
\hline Plate A & 12.535 & 0.313 & 12.643 & 0.289 & 12.342 & 0.268 & 12.620 & 0.150 \\
\hline Plate K & 12.035 & 0.201 & 12.158 & 0.157 & 11.853 & 0.151 & 12.095 & 0.150 \\
\hline Plate U & 12.518 & 0.219 & 12.620 & 0.023 & 12.378 & 0.200 & 12.556 & 0.187 \\
\hline Spine 3 & 13.225 & 0.288 & 13.250 & 0.249 & 13.119 & 0.275 & 13.307 & 0.304 \\
\hline Spine 6 & 12.743 & 0.339 & 12.849 & 0.346 & 12.674 & 0.356 & 12.704 & 0.282 \\
\hline Spine 9 & 12.340 & 0.269 & 12.381 & 0.182 & 12.192 & 0.292 & 12.446 & 0.254 \\
\hline Spine 12 & 13.151 & 0.236 & 13.290 & 0.186 & 13.005 & 0.224 & 13.157 & 0.207 \\
\hline
\end{tabular}

Data maps that locate the position and values of dynamic Young's modulus for each specimen are presented in Figures 14a to 17d. The plate sections are distributed between Figures 14a to 15c, and the results for the spines can be found in Figures 16a to 17d.

The lowest dynamic Young's modulus values can be found in Figure 14e, these values correspond to the dynamic Young's modulus in the y direction for plate $\mathrm{K}$. The higher values were found in spine 3 for the $\mathrm{x}$ direction (Figure 16a) and spine 12, also in the $\mathrm{x}$ direction (Figure 17d). The dynamic Young's modulus maps follow similar patterns to the ones found in the density maps. Furthermore, the higher values of dynamic Young's modulus found at the edges of the billet correspond to the high density values found at the exterior of the billet. Figure 18 shows the positive correlation found between density and dynamic Young's modulus, as well as some linear regression models.

The highest density and dynamic Young's modulus can be found at plate A. Similar elastic modulus behaviour can be found at the samples of plate $U$, although the density values are lower than Plate A or K. This concentration of higher modulus of elasticity values at plate $\mathrm{U}$ may be due 
to its proximity to the edge of the billet. A different microstructure may arise at the exterior of the billet due to the manufacturing process, causing a higher stiffness at this region. This may also explain why the centre of the billet or plate $\mathrm{K}$ may have a higher density but a lower elastic modulus. This particular region of the billet, plate $\mathrm{K}$, displays a higher scatter in the relationship between density and elastic modulus.

A plot of Young's modulus across of the billet is represented in Figure 19; this figure shows the variability of this property through the height of the billet. 

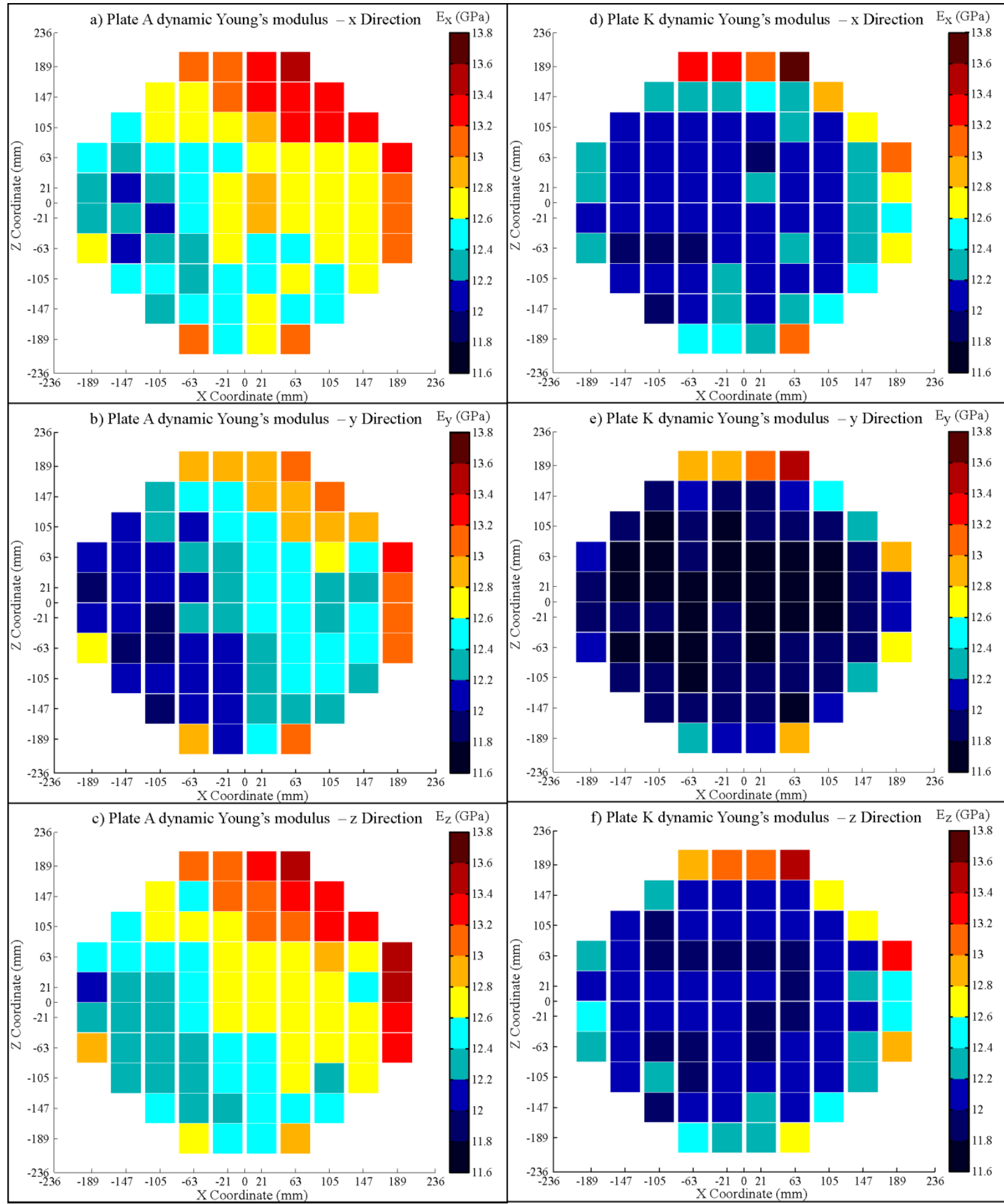

Figure 14. Map for the dynamic Young's modulus (DYM) distribution for the plate A and K sections. a) Plate A DYM in the $\mathrm{x}$ direction, b) Plate A DYM in y direction, c) Plate A DYM in z direction, d) Plate K DYM in the x direction, e) Plate K DYM in the y direction, f) Plate U DYM in the $\mathrm{z}$ direction. 

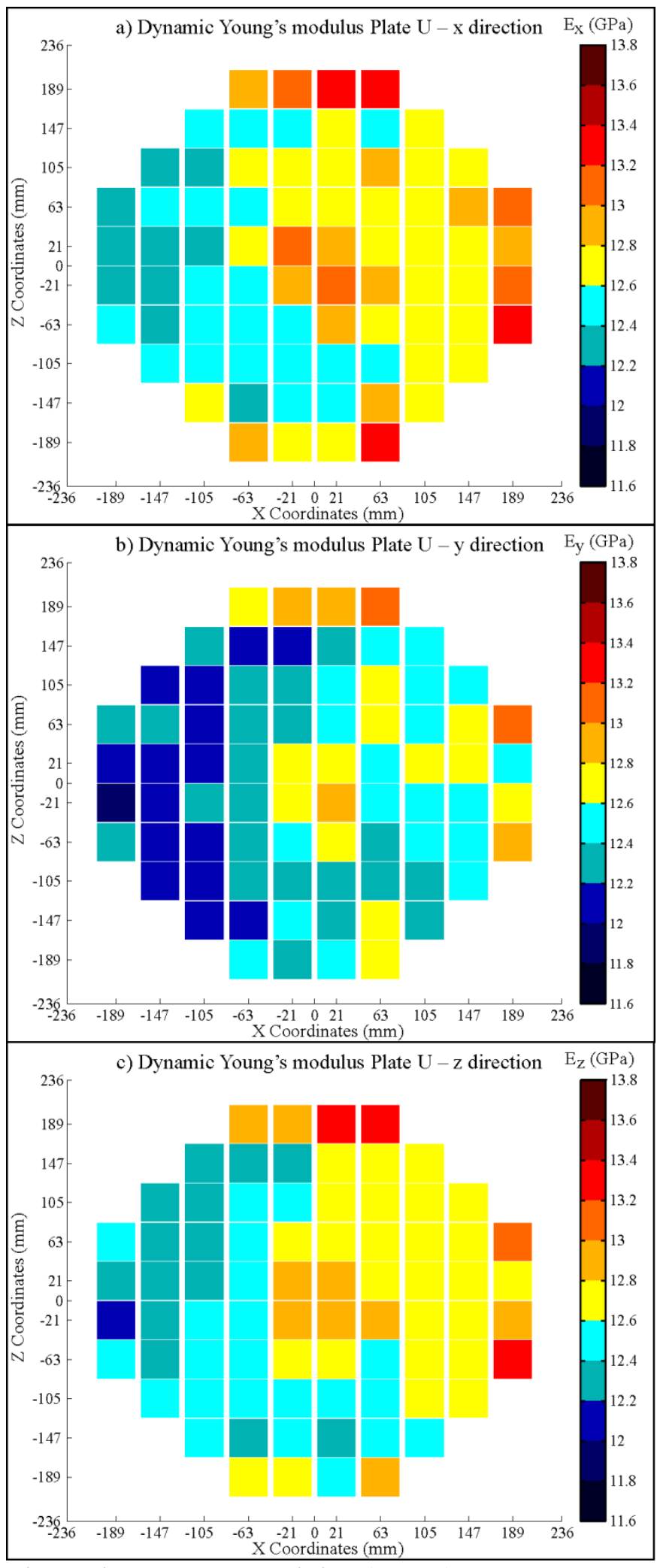

Figure 15. Map for the dynamic Young's modulus (DYM) distribution for the plate U. a) Plate U DYM in the $\mathrm{x}$ direction, b) Plate U DYM in y direction, c) Plate U DYM in the $\mathrm{z}$ direction 


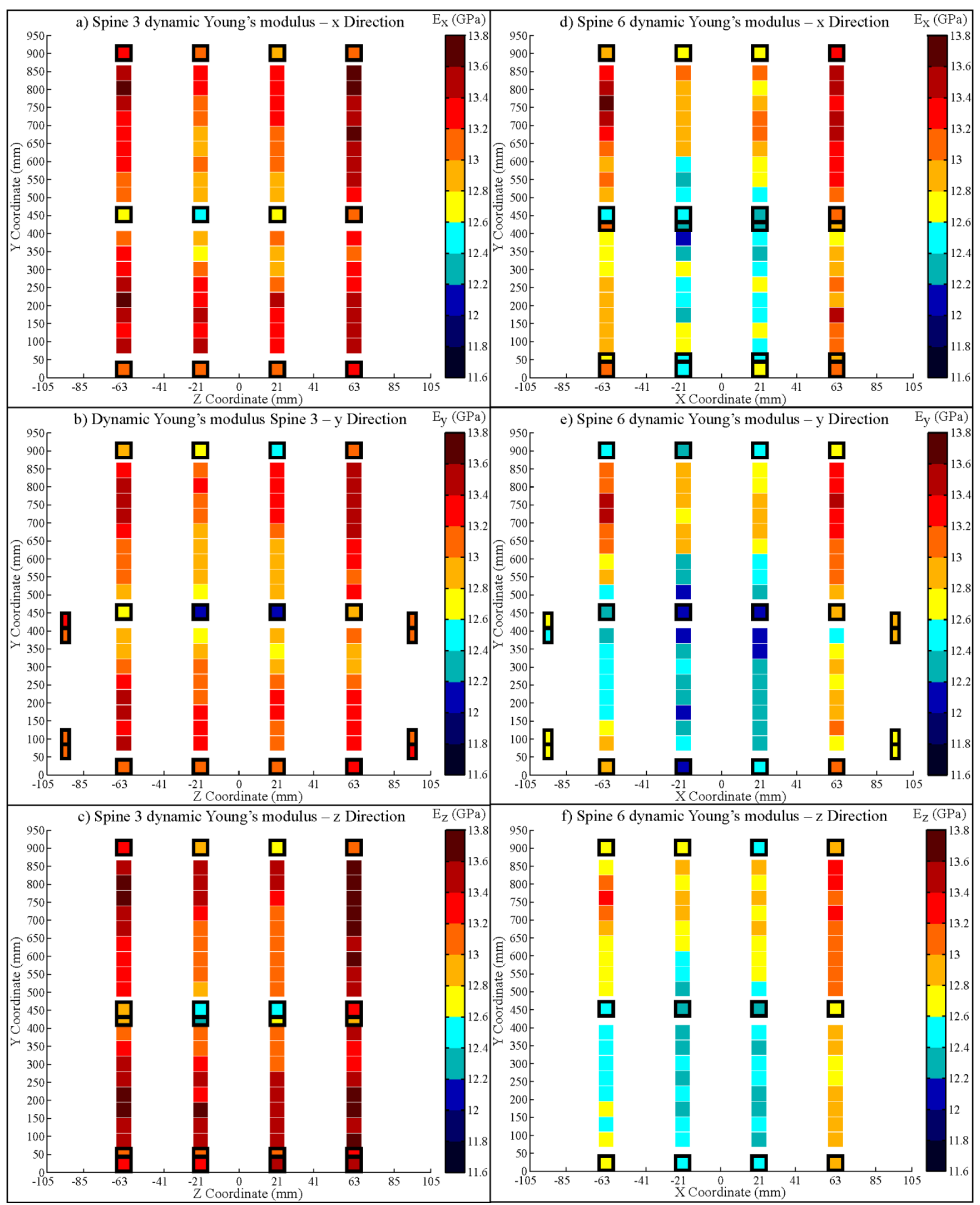

Figure 16. Map for the Dynamic Young's modulus (DYM) distribution for the spine sections. a) Spine 3 DYM in $x$ direction, b) Spine 3 DYM in y direction, c) Spine 3 DYM in z direction, d) Spine 6 DYM in $\mathrm{x}$ direction, e) Spine 6 DYM in y direction f) Spine 6 DYM in $\mathrm{z}$ direction 


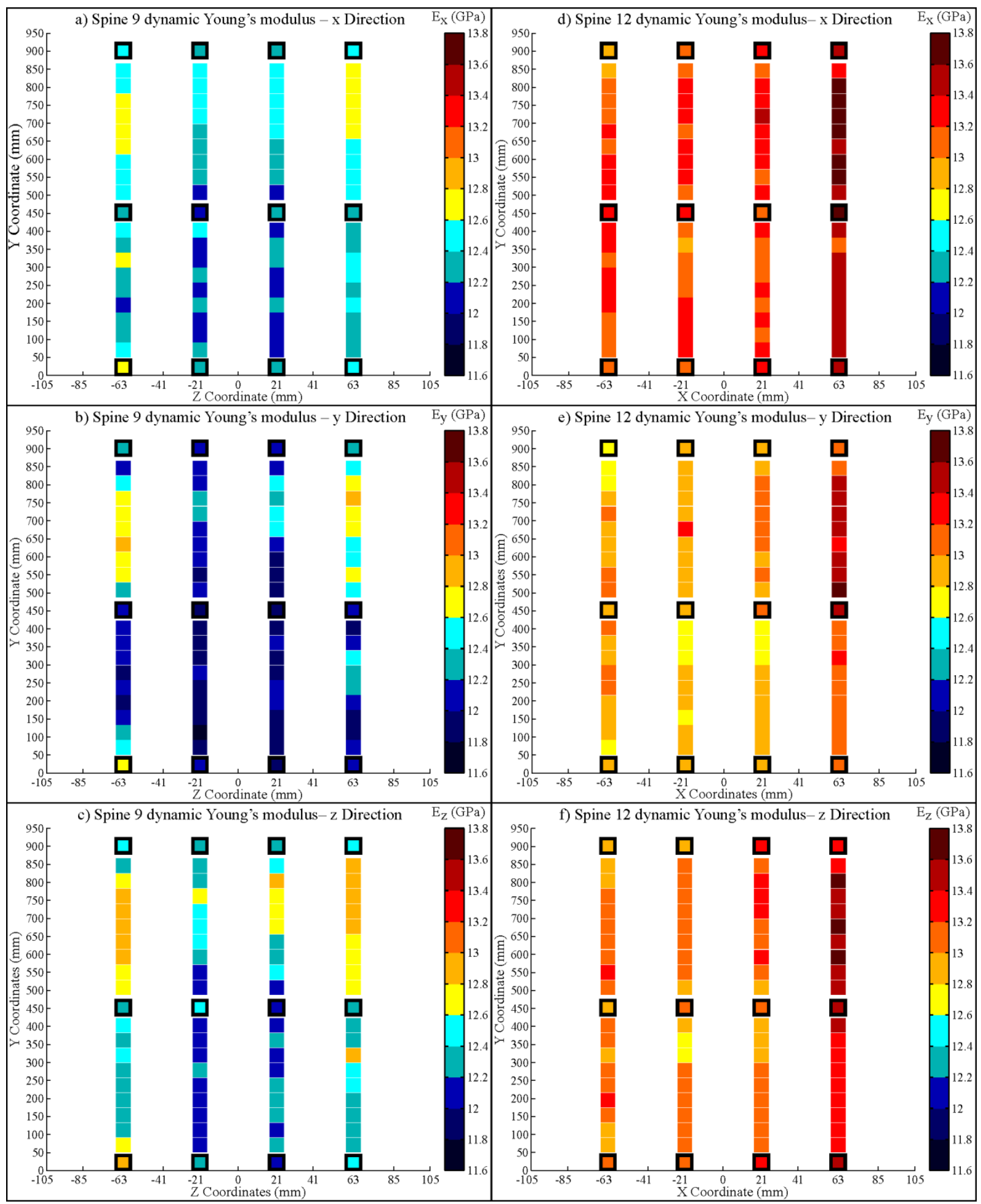

Figure 17. Map for Dynamic Young's modulus (DYM) distribution for the spine sections. a) Spines 9 DYM in $\mathrm{x}$ direction, b) Spines 9 DYM in y direction, c) Spines 9 DYM in z direction, d) Spines 12 DYM in $x$ direction, e) Spines 12 DYM in y direction, f) Spines 12 DYM in z direction 


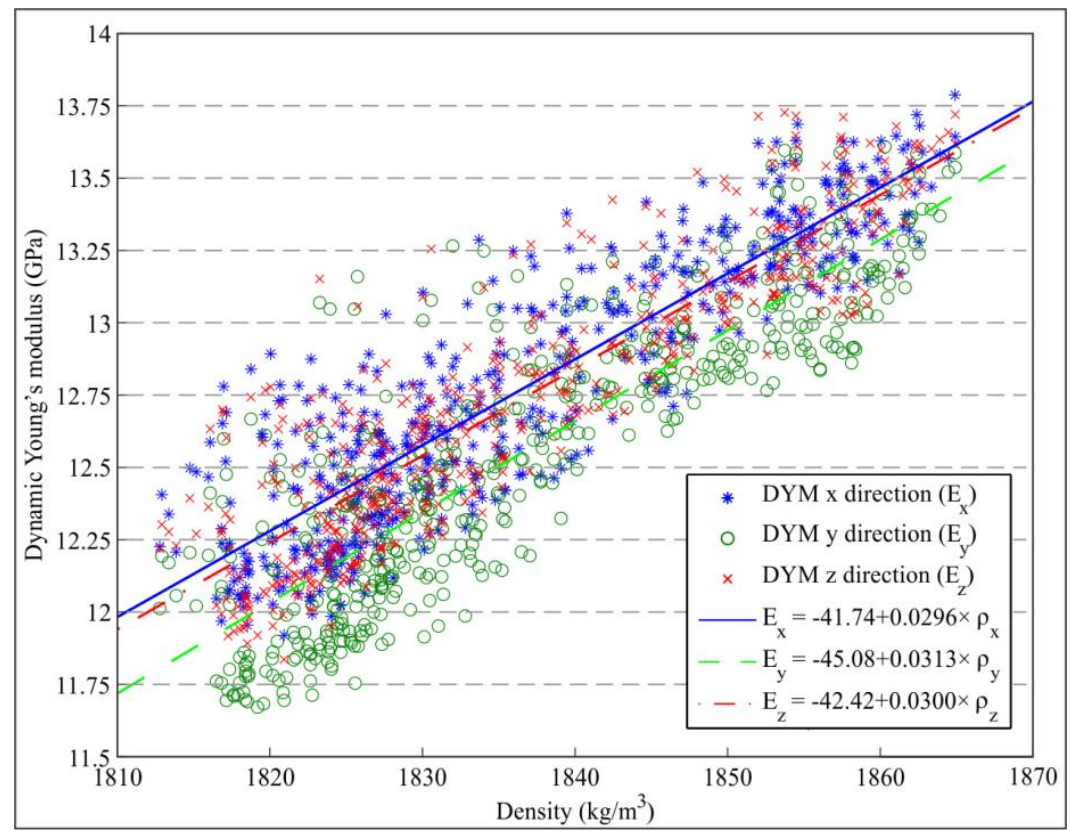

Figure 18. Dynamic Young's modulus versus density for all the data

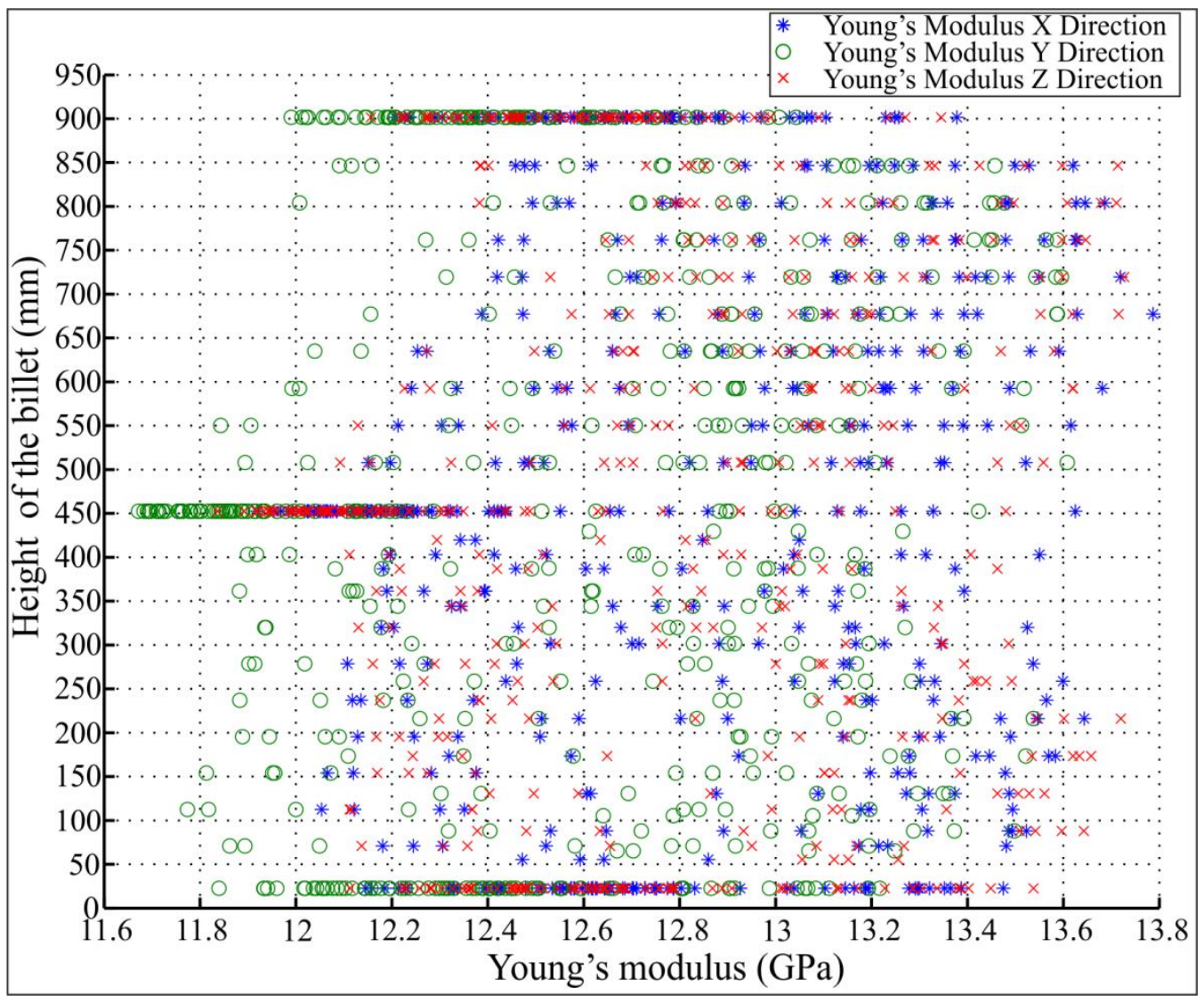

Figure 19. Variation of Young's modulus through the height of the billet 


\section{Discussion}

\subsection{Density}

Density is an important variable that influences other physical and mechanical properties. Relationships between density, Young's modulus and thermal expansion have been found for several types of nuclear graphite. The findings of Yoda and Fujisaki [27] show that low values of density in nuclear graphite correspond to low values of the coefficient of thermal expansion and Young's modulus and vice versa.

The small standard deviation in values obtained can be interpreted as small density variations through a section. As can be seen from Figure $6 a$ to $6 \mathrm{c}$ the centres of the billets tend to have density values lower than the exterior of the plates. The figures show that density values fluctuate at different heights of the billet. This effect might be caused during the impregnation stage of the manufacturing process that increases the density at the exterior of the billet. This idea is supported by the density data in Figure 8, the data points that belong to the plates have lower values than the spine sections. Figure 8 also shows the scatter of density values due to the position of the specimens. Higher density values are present in the spine sections compared to the plates, as can be seen from Figures $7 \mathrm{a}$ to $7 \mathrm{~d}$. These sections are closer to the edge of the billet as is shown in Figure $3 b$. The variations of density may be aligned with the pressing direction causing more dense regions at the exterior of the billet as well as different density distributions across the height of the billet.

Normality tests were performed for the whole data set using three standard functions in Matlab (2013a, The MathWorks) and a normal probability plot (Figure 20). It is important to note that for spatial data, there is a potential for bias from statistical independence. The assumption of statistical independence was made for all the statistical analysis carried out in this paper. The Matlab functions used were kstest (one-sample Kolmogorov-Smirnov test [28]), jbtest (Jarque-Bera test $[29,30])$ and lillietest (Lilliefors test [31, 32]). All of these tests rejected the null hypothesis that the density data belongs to a family of normal distributions. In the normal probability plot, a straight line was drawn between the first and third quartiles and compared with the cumulative 
normal probability of the density data points. The normality plot points deviate from a theoretical straight line proving that the density data points do not belong to a normal distribution.

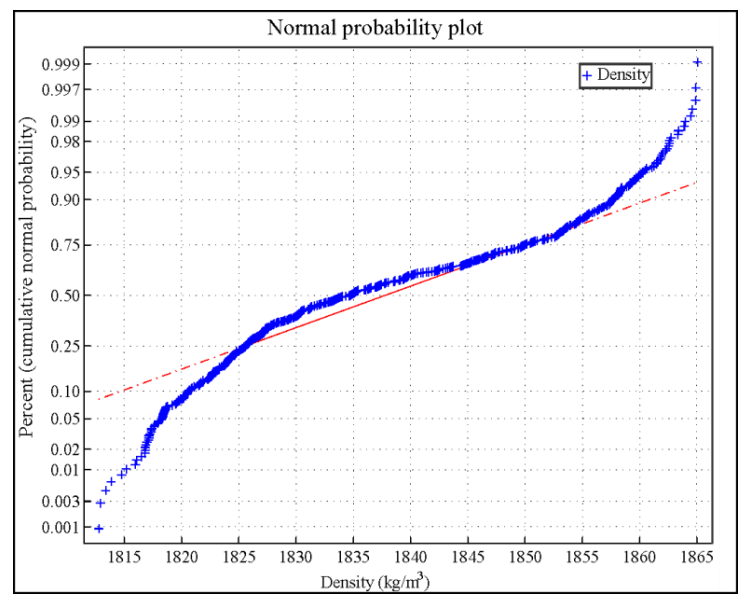

Figure 20. Normal probability plot of all density experimental values

The whole density data set was also used to create a histogram using the Freedman-Diaconis rule [33] and a non-parametric probability density function (Figure 21a). The large number of specimens with high density values in the spine sections results in a non-symmetric probability density distribution. Lognormal distributions were fitted to the plate and spine density data sets (Figure 21b). 

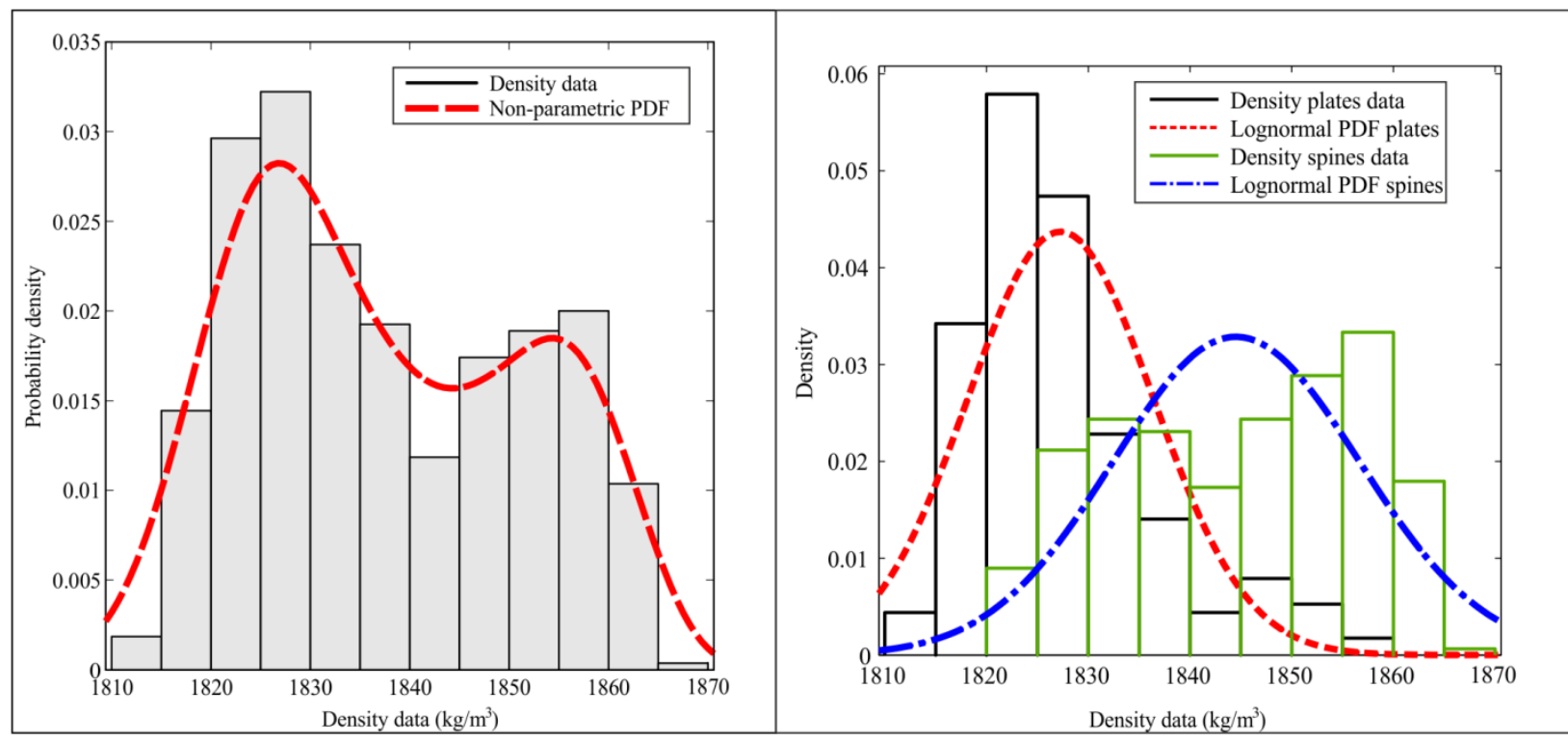

Figure 21. Probability density functions for density data. a) Probability density function for the density data and histogram created with the Freedman-Diaconis rule. b) Lognormal distributions for plates and spines density data

The density data can be treated as two independent subsets to demonstrate that there is a difference between the values of the material properties at the edge and the inside of the billet. The first data subset includes the spine sections (328 specimens) that tend to have higher density values. The second includes the plate sections (180 specimens) which have a lower average density. Figure 22 shows which specimens belong to the plate and spine sections.

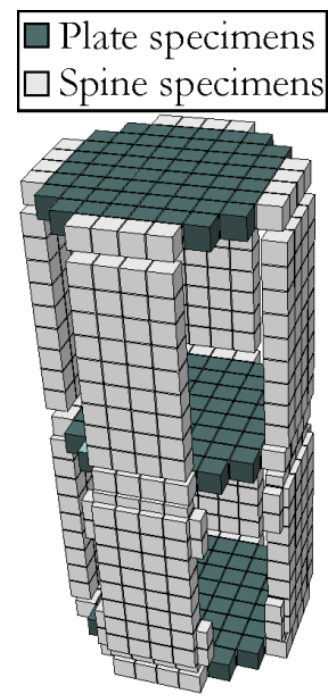

Figure 22. Specimens assigned for each section 
A normality test for density values of the plates and spines was performed by drawing a normality plot and comparing with a theoretical line, as described previously. The normality tests showed that both plate and spine experimental data points do not belong to a normal distribution, because the curves formed by the accumulative normal points deviated from the straight line.

Using the Matlab function vartestn( , 'LeveneAbsolute'), Levene's test [34] was used to prove the null hypothesis that the variances of the plate $\left(\sigma_{\rho \mathrm{P}}\right)$ and spine section $\left(\sigma_{\rho \mathrm{S}}\right)$ densities were equal $\left(H_{0}: \sigma^{2} \rho_{P}=\sigma^{2} \rho_{S}\right)$ or prove the alternative hypothesis that the variances are different $\left(H_{1}: \sigma_{\rho P}^{2} \neq \sigma_{\rho S}^{2}\right)$. The mean $\mu$, standard deviation $\sigma$ and number of samples $n$ for the plate data set were $\mu_{\rho \mathrm{P}}=1824.95$ $\mathrm{kg} / \mathrm{m}^{3}, \sigma_{\rho \mathrm{P}}=7.19 \mathrm{~kg} / \mathrm{m}^{3}$ and $\mathrm{n}_{\rho \mathrm{P}}=180$ and for the spine data $\mu_{\rho \mathrm{S}}=1843.51, \sigma_{\rho \mathrm{S}}=12.22$ and $\mathrm{n}_{\rho \mathrm{S}}=$ 360. The Levene's test was performed with a significance level of 5\%. The test rejected the null hypothesis with a p-value $<0.001,1538$ degrees of freedom and an absolute Levene's statistic of 117.693. A p-value lower than the significance level mean (here 5\%) means that the null hypothesis can be rejected.

To compare the central tendencies of the data in the spines and plates a two-sided Mann-Whitney U-test $[35,36]$ was calculated in Matlab at a 5\% significance level. The function ranksum proves the null hypothesis that the two medians are equal and provides the $\mathrm{p}$ value and $\mathrm{z}$-statistic for large samples, as found in this case. The hypothesis that the plate median $1824.08 \mathrm{~kg} / \mathrm{m}^{3}$ and spine median $1844.54 \mathrm{~kg} / \mathrm{m}^{3}$ were statistically equal was rejected with $\mathrm{p}<0.001$ and a $\mathrm{z}$-statistic of 15.3746.

The statistical tests showed that the density values of the plates and spines have statistically different variances and medians. This helps to support the idea that there is a difference between the density values of the spines and the plates.

Figure 23 shows that the average values of density for Gilsocarbon nuclear graphite components obtained from heat certificates differ from our study. The standard deviations are similar for the first three power stations as shown in Figure 23. However, the average for the plate sections is closer to the heat certificates data. Only the standard deviation for Heysham II/Torness is higher 
than the new values presented in this paper. Differences between density values may be due to differences in the size and geometry of the samples used during the measurements as well as the regions that were sampled. In the case of the Dungeness B heat certificate data, a whole brick was used to determine its density and geometry [37] and importantly, the value obtained is one single value for the whole volume.

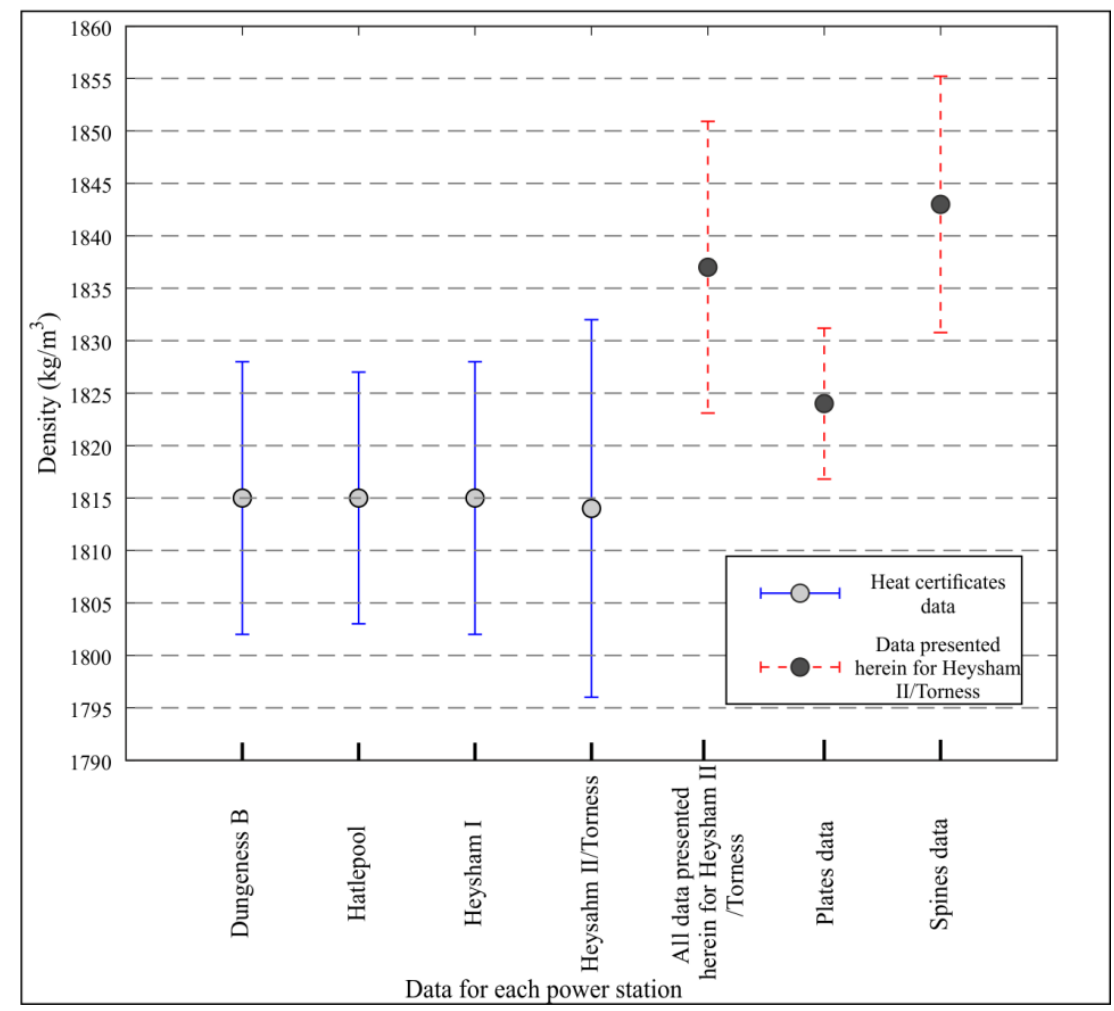

Figure 23. Comparison of the average density values for Gilsocarbon nuclear graphite components obtained from heat certificates [10] and the authors values presented herein. The bars indicate one standard deviation.

\subsection{Dynamic Poisson's ratio}

Dynamic techniques have been previously used to measure the dynamic Poisson's ratio [17, 20, $25]$ and dynamic shear modulus of graphite [20,38]. Poisson's ratio is a material property that is not recorded during the manufacture of the graphite components $[4,11]$, but it is a necessary parameter for understanding the mechanical behaviour of nuclear graphite. 
From the map for dynamic Poisson's ratio (Figures 10-11) and Table 3 we can see that there is spatial variation of this material property through the plates. Most of the values in the $\mathrm{x}$ and $\mathrm{z}$ direction are in the range of 0.2103 and 0.2310 and the averages are 0.2206 and 0.2201 for $\mathrm{x}$ and $\mathrm{z}$ directions respectively. These dynamic Poisson's ratio values are between the range reported by Preston [39] $0.22 \pm 0.01$ and similar to the value of 0.21 quoted by Brocklehurst [40]. These values also indicate a very similar behaviour in the orthogonal directions. Lower values of dynamic Poisson's ratio were found in the y direction, with an average of 0.2133.

\subsection{Dynamic shear modulus}

Marlowe [38] measured the Young's modulus and shear modulus of three grades of graphite, ATJS, POCO 5Q, and POCO 9Q at room temperature and at $2000{ }^{\circ} \mathrm{C}$. All of the measurements were carried out using the sonic resonant frequency technique. As a result of these experiments, the researchers found that the dynamic shear modulus and dynamic Young's modulus are directly proportional to the density values for these grades of graphite. Our shear modulus values averaged 5.1356 GPa, 5.0437 GPa and 5.1219 GPa in the $\mathrm{x}, \mathrm{y}$ and $\mathrm{z}$ directions respectively. Our data also shows a relationship between the density and dynamic shear modulus, similar to the relationship reported by Marlowe [38] for other grades of graphite. Figure 11 and Table 4 show a significant variation of dynamic shear modulus across plates $\mathrm{A}, \mathrm{K}$ and $\mathrm{U}$ of about $13 \%$ between the lowest and highest values.

\subsection{Dynamic Young's modulus}

Higher values of dynamic Young's modulus were found at the edges of the billet; similar to the pattern observed in the density values. The dependency of elastic modulus on density is explained by the effect of porosity in graphite. A relationship between porosity and Young's modulus in graphite can be found in reference [41] and for other polycrystalline materials in [42, 43]. These are due to changes in microstructure (in certain locations) that may be produced during the moulding process [14]. As with the variations in density, Dynamic Young's modulus values can be observed to vary at different heights of the billet (Figure 19). The trend of the data is similar to the one found by Mostafavi and Marrow for strength values [14]. 
The same statistical analysis conducted for the density data was repeated for the dynamic Young's modulus data. The purpose of this analysis was to determine if the dynamic Young's modulus is normally distributed and show if there is a significant difference between the exterior and interior the billet, following the criteria shown in Figure 22. The one-sample Kolmogorov-Smirnov test, Jarque-Bera test and Lilliefors test investigated the null hypothesis that the dynamic Young's modulus data belong to a family of the normal distribution at 5\% significance level. All the tests rejected the null hypothesis proving that the Young's modulus data do not belong to a type of normal distribution.

As before, the dynamic Young's modulus data was treated as separate spine and plate data sets for further statistical analysis. The aim is to determine the possible statistical differences between the plates and spines. As was done previously with the density data the dynamic Young's modulus variances and medians of the plates and spines sections were compared. This statistical analysis would help to demonstrate if the exterior of the billet has a different mechanical behaviour than the immediately adjacent interior cubes and the centre of the billet. Levene's test was used to analyse if the variances between the spines ( $\sigma^{2}$ DYMS $)$ and plates sections ( $\sigma^{2}$ DYMP) for dynamic Young's modulus were equal $\left(\mathrm{H}_{0}: \sigma^{2}{ }_{\text {DYMS }}=\sigma^{2}\right.$ DYMP). The Levene's test with $p$ value $<0.001$ and a $5 \%$ significance rejected the null hypothesis showing that the variance of the spines and plates sections are not equal. The mean, standard deviation and number of samples were $\mu_{\mathrm{DYMP}}=12.36$ $\mathrm{GPa}, \sigma_{\mathrm{DYMP}}=0.34 \mathrm{GPa}$ and $\mathrm{n}_{\mathrm{DYMP}}=540$ for the plate sections, and $\mu_{\mathrm{DYMS}}=12.84 \mathrm{GPa}, \sigma_{\mathrm{DYMS}}=$ $0.45 \mathrm{GPa}$ and $\mathrm{n}_{\mathrm{DYMS}}=1016$ for the spines.

The Mann-Whitney U-test was used to test the hypothesis at 5\% significance level that the dynamic Young's modulus of the plate and spine data sets medians are equal, against the alternative hypothesis that the medians are not equal. The null hypothesis was rejected with a $p$ value $<0.001$, demonstrating that the medians of the plates and spines can be treated as two different sampling populations and therefore these sections would have a different elastic mechanical behaviour.

Figure 24 compares our mean values of Young's modulus with data from heat certificates. The values reported by Preston [10] are described as longitudinal and transversal to the press direction. For this study the $\mathrm{x}$ and $\mathrm{z}$ direction are equivalent to the transversal direction, and the $\mathrm{y}$ direction 
to the longitudinal direction. The authors can only confirm that the Dungeness B Young's modulus measurements for heat certificates were measured with the same technique used in this paper, meaning the only differences between the dynamic technique measurement and those collected for this purpose are the size and geometry of the specimens [37]. Our mean values of dynamic Young's modulus are higher than the values found in previous studies, although the values for the plates sections are comparable between the new data and older data. This difference can be explained by the fact that in this research a larger number of samples were taken at the exterior increasing the mean value for dynamic Young's modulus. The average values of the plates are closer to the ones tested during the manufacture of graphite components.

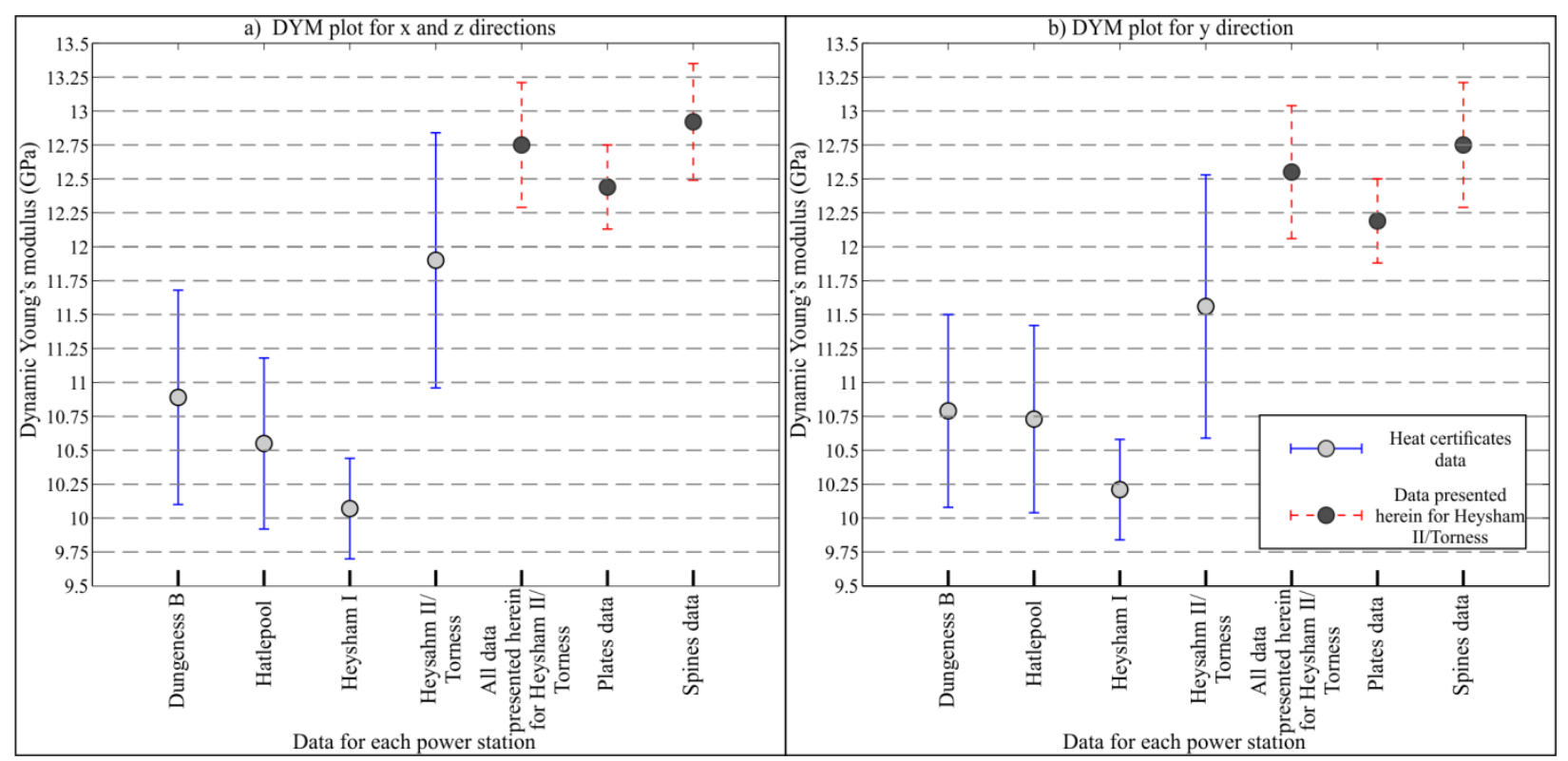

Figure 24. Comparison of the average values for dynamic Young's modulus for Gilsocarbon nuclear graphite components obtained from heat certificates [10] and this study. The bars indicate one standard deviation.

\subsection{Anisotropy of the material}

The ratios between each orthogonal direction were computed (Table 5) in order to quantify the degree of anisotropy for all material properties. 
Table 5. Isotropy ratio for all material properties

\begin{tabular}{|c|c|c|c|c|c|c|c|c|}
\hline \multicolumn{3}{|c|}{$\begin{array}{c}\text { Dynamic Poisson's } \\
\text { ratio }\end{array}$} & \multicolumn{3}{c|}{$\begin{array}{c}\text { Dynamic shear modulus } \\
(\mathrm{GPa})\end{array}$} & \multicolumn{3}{c|}{$\begin{array}{c}\text { Dynamic Young's modulus } \\
(\mathrm{GPa})\end{array}$} \\
\hline$v_{\mathrm{x}} / \mathrm{v}_{\mathrm{y}}$ & $\mathrm{v}_{\mathrm{z}} / \mathrm{v}_{\mathrm{y}}$ & $\mathrm{v}_{\mathrm{x}} / \mathrm{v}_{\mathrm{z}}$ & $\mathrm{G}_{\mathrm{x}} / \mathrm{G}_{\mathrm{y}}$ & $\mathrm{G}_{\mathrm{z}} / \mathrm{G}_{\mathrm{y}}$ & $\mathrm{G}_{\mathrm{x}} / \mathrm{G}_{\mathrm{z}}$ & $\mathrm{E}_{\mathrm{x}} / \mathrm{E}_{\mathrm{y}}$ & $\mathrm{E}_{\mathrm{z} / \mathrm{E}_{\mathrm{y}}}$ & $\mathrm{E}_{\mathrm{x}} / \mathrm{E}_{\mathrm{z}}$ \\
\hline 1.036 & 1.033 & 1.003 & 1.002 & 1.015 & 1.014 & 1.017 & 1.014 & 1.002 \\
\hline
\end{tabular}

The largest anisotropy was found for the dynamic Poisson's ratio for the $\mathrm{x}$ and $\mathrm{y}$ directions with a value of 1.036. All of the anisotropy ratios for the dynamic Poisson's ratio were higher than for the dynamic shear modulus or the dynamic Young's modulus, where these last two properties have very similar values. Table 5 suggests that the highest degree of anisotropy can be found for Poisson's ratio data points. ASTM D7219-08 [44] provides a classification of the degree of isotropy for nuclear graphite with respect to the coefficient of thermal expansion. Isotropic nuclear graphite grades require an isotropic ratio for coefficient of thermal expansion between 1.00 to 1.10. Extending this criterion to the measurements done in this study it can be considered that all material properties have an isotropic behaviour.

Other possible anisotropic behaviour of the billet was investigated by calculating the correlation coefficient of pairs of data points. This possible gradient or preferential orientation was identified by a visual inspection of Figures 6,14 and 15 in the Southwest to Northeast direction. To identify this trend the data points were paired in two different ways in a South to North direction and a Southwest to Northeast direction, the configurations for which are shown in Figure 25. The arrows of Figure 25 symbolise vectors, which in this case shows how the data points were paired. The data point located at the tail of the vector was paired with arrow head or end of the vector. This procedure was done by all data points to calculate the correlation coefficient for density and dynamic Young's modulus in all directions (Table 6). 


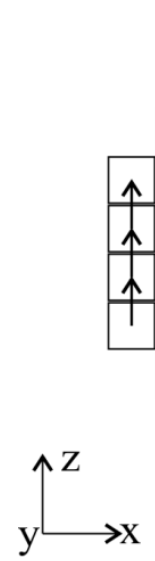

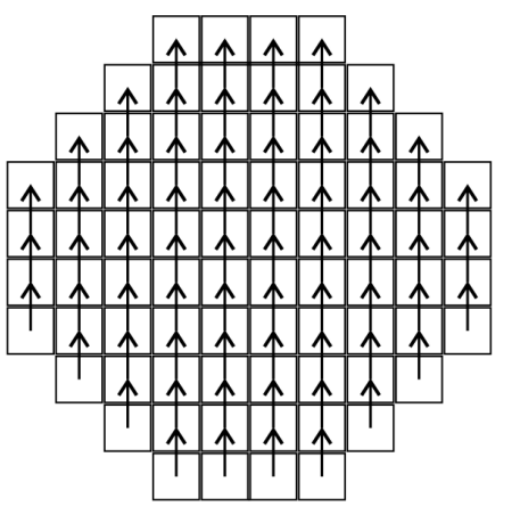

a) South - North configuration

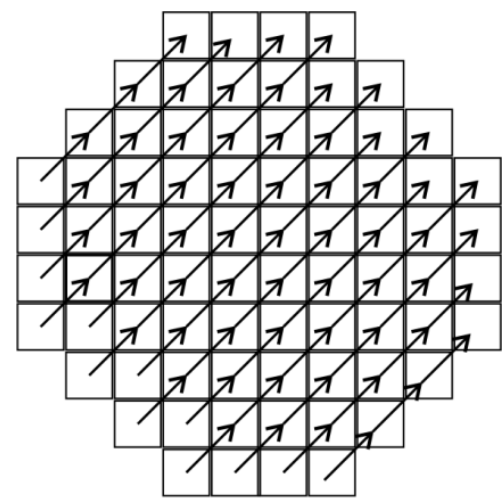

b) Southwest - Northeast configuration

Figure 25. Configurations to pair data points and for the calculations of the correlation coefficients

Table 6. Correlation coefficient for density and dynamic Young's modulus

\begin{tabular}{|c|c|c|c|c|c|c|}
\cline { 2 - 7 } \multicolumn{1}{c|}{} & \multicolumn{2}{c|}{ Plate A } & \multicolumn{2}{c|}{ Plate K } & \multicolumn{2}{c|}{ Plate U } \\
\cline { 2 - 7 } & $\begin{array}{c}\text { South }- \\
\text { North } \\
\text { config. }\end{array}$ & $\begin{array}{c}\text { SW - NE } \\
\text { config. }\end{array}$ & $\begin{array}{c}\text { South }- \\
\text { North } \\
\text { config. }\end{array}$ & $\begin{array}{c}\text { SW - NE } \\
\text { config. } \\
\text { Nouth - } \\
\text { North } \\
\text { config. }\end{array}$ & $\begin{array}{c}\text { SW - } \\
\text { NE } \\
\text { config. }\end{array}$ \\
\hline Density & 0.8073 & 0.7847 & 0.3941 & 0.4048 & 0.3189 & 0.1280 \\
\hline$E_{X}$ & 0.7912 & 0.7739 & 0.7405 & 0.6733 & 0.8252 & 0.7752 \\
\hline$E_{Y}$ & 0.3759 & 0.4003 & 0.2392 & 0.3317 & 0.3001 & 0.3645 \\
\hline$E_{Z}$ & 0.5457 & 0.4242 & 0.5833 & 0.4517 & 0.5591 & 0.4145 \\
\hline
\end{tabular}

Table 6 compares the correlation coefficient for all density and dynamic Young's modulus values. These coefficients show that in most of the cases the correlation in the Southwest to Northeast direction are lower than the South to North direction. This means that the possible preferential orientation in the Southwest to Northeast direction is smaller than the $\mathrm{z}$ orthogonal direction established for this study. Therefore, the Southwest to Northeast preferential orientation of mechanical properties was not considered in this study.

\section{Summary and conclusions}

The spatial variation in density, dynamic Young's modulus, dynamic Poisson's ratio and dynamic shear modulus was investigated for a single virgin Gilsocarbon nuclear graphite billet that was manufactured for use in the Torness/Heysham II nuclear power station. 
The main findings of this paper are presented below:

1. Mensuration was used to determine the density of 508 cubes and 32 rectangular prisms. Higher density values were found at the edges of the billet. Density variations were found at different heights of the billet. It was found that the mean values in the heat certificates are lower than those measured in this study.

2. Time of flight techniques were used to calculate the dynamic Poisson's ratio and dynamic shear modulus of 228 specimens. The value of dynamic Poisson's ratio was 0.21 parallel to the $y$ direction and 0.22 in the $\mathrm{x}$ and $\mathrm{z}$ directions. These values were in the range reported by Preston for the same type of billet [39]. The value of dynamic shear modulus varied across the plates, the average value was $5.09 \mathrm{GPa}$ with a standard deviation of $0.13 \mathrm{GPa}$.

3. The dynamic Young's modulus for each specimen was measured with a time of flight technique in all three orthogonal directions for the cubic specimens and one direction along the longest side of the rectangular prisms. Higher values of dynamic Young's modulus were found at the exterior of the billet. The mean value of dynamic Young's modulus obtained by the authors was higher than values reported previously [10].

4. The density and Young's modulus data sets were tested for normality. Neither of the data sets followed a normal distribution.

5. The median and variance of the density and Young's modulus of the edges represented by the spines and centre of the billet formed by the plate sections (Figure 21) were found to be significantly different.

6. The density and dynamic Young's modulus data values were in the range recommended by the ASTM Standard Specification for Isotropic and Near-isotropic Nuclear Graphites D721908(2014) [44]. 
In conclusion, we can state that there is a significant spatial variation in the material properties of this particular billet of nuclear graphite. Our investigation focuses on a single billet and a larger number of billets will need to be tested to take into account variations between billets that might arise during the manufacturing process. An important finding was that a difference in dynamic Young's modulus was identified between the edge and the interior of the billet. Future work could involve studying the microstructure to confirm our belief that microstructure and material properties are closely related. The results are significant both from the point of view of the structural integrity of existing reactors and the assumptions made in computer models of reactor components. The spatial variation in elastic stiffness will generate non-zero pre-service stresses in virgin Gilsocarbon bricks subject to simple temperature changes. These stresses arise due to material incompatibilities. The variability may also have an effect on predictions of graphite ageing; fast-neutron flux profiles and temperature profiles vary through a graphite brick and also from brick to brick in a reactor core. Lifetime predictions of Gilsocarbon assume isotropic mean values for material properties. The variability may mean that the material response is more complicated than is accounted for in state-of-the-art models of nuclear graphite behaviour. Furthermore, computer modelling of graphite components may predict different outcomes to standard analyses (that use mean values) if this variability is incorporated into the analysis workflow; specifically through stochastic modelling, which was the original motivation for this work.

\section{Acknowledgements}

The authors wish to thank the support and resources provided by the Mexican National Science and Technology Council (CONACYT) and EPSRC through grant QUBE: Quasi-brittle fracture: a 3D experimentally-validated approach (EP/JO19763). The authors also want to acknowledge the contributions of Alan Steer and EDF Energy Generation for providing the billet for this study. The authors would also like to thank the staff of Erodex (UK) Ltd, especially to John Webb, Lee Chivers and Paul Angel for helping us to machine the specimens used in this research. 


\section{References}

[1] Marsden BJ, Hall GN. 4.11 - Graphite in Gas-Cooled Reactors. In: Konings RJM, ed. Comprehensive Nuclear Materials. Oxford: Elsevier 2012, p. 325-90.

[2] Nightingale RE. Nuclear graphite. New York ; London: Academic Press; 1962.

[3] Steer AG. AGR core design, operation and safety functions. Roy Soc Ch. 2007(309):11-8.

[4] Neighbour GB. Plant life management (PLiM) practices for gas-cooled, graphitemoderated nuclear reactors: UK experience. Woodhead Publ Ser En. 2010(4):838-75.

[5] Nonbøl E. Description of the Advanced Gas Cooled Type of Reactor (AGR). Roskilde, Denmark: Risø National Laboratory; 1996.

[6] McNally K, Hall G, Tan E, Marsden BJ, Warren N. Calibration of dimensional change in finite element models using AGR moderator brick measurements. Journal of Nuclear Materials. 2014;451(1-3):179-88.

[7] Arregui-Mena JD, Margetts L, Griffiths DV, Lever L, Hall G, Mummery PM. Spatial variability in the coefficient of thermal expansion induces pre-service stresses in computer models of virgin Gilsocarbon bricks. Journal of Nuclear Materials. 2015;465:793-804.

[8] Arregui-Mena J, Margetts L, Mummery P. Practical Application of the Stochastic Finite Element Method. Arch Computat Methods Eng. 2014:1-20.

[9] AGENCY IAE. Irradiation Damage in Graphite due to Fast Neutrons in Fission and Fusion Systems. Vienna: INTERNATIONAL ATOMIC ENERGY AGENCY; 2000.

[10] Preston SD. The effect of material property variations on the failure probability of an AGR moderator brick subject to irradiation induced self stress. Univeristy of Salford, PhD, 1989.

[11] Preston SD. The statistical variation present in the material properties of Dungeness, Hartlepool, Heysham I and Heysham II/ Torness CAGR moderator graphites United Kingdom Atomic Energy Authority Northern Division; 1986. Report No.: ND-M-3008(S).

[12] Preston SD. Variation of material properties within a single brick of the Heysham 2/Torness moderator graphite: United Kingdom Atomic Energy Authority Northern Division; 1988. Report No.: ND-M-3755(S).

[13] Novovic M, Bowen P. Compressive Strength of Graphite Report - March 2013. Birmingham: University of Birmingham; 2013.

[14] Mostafavi M, Marrow TJ. Quantitative in situ study of short crack propagation in polygranular graphite by digital image correlation. Fatigue \& Fracture of Engineering Materials \& Structures. 2012;35(8):695-707.

[15] Cressie NAC. Statistics for spatial data. Rev. ed. ed. New York ; Chichester: Wiley; 1993.

[16] Wang JF, Stein A, Gao BB, Ge Y. A review of spatial sampling. Spat Stat-Neth. 2012;2:1-

14.

[17] Carroll M, Lord J, Rohrbaugh D. Baseline Graphite Characterization: First Billet. United States: Idaho National Laboratory; 2010. Report No.: INL/EXT-10-19910 TRN: US1100212.

[18] West EA, Was GS. Strain incompatibilities and their role in intergranular cracking of irradiated 316L stainless steel. Journal of Nuclear Materials. 2013;441(1-3):623-32.

[19] ASTM. ASTM C559-90(2010), Standard Test Method for Bulk Density by Physical Measurements of Manufactured Carbon and Graphite Article. West Conshohocken, PA 2010.

[20] Bodel W. The relationship between microstructure and Young's modulus of nuclear graphite. The University of Manchester, PhD, 2013. 
[21] Oku T, Eto M. Relation between static and dynamic Young's modulus of nuclear graphites and carbon. Nuclear Engineering and Design. 1993;143(2-3):239-43.

[22] Wouters O. Development of Dynamic Young's Modulus Test Setup for Irradiated and Oxidised Graphite. In: Neighbour GB, ed. Securing the Safe Performance of Graphite Reactor Cores: The Royal Society of Chemistry 2010, p. 111-7.

[23] Yoda S, Eto M, Oku T. Change in dynamic young's modulus of nuclear-grade isotropic graphite during tensile and compressive stressing. Journal of Nuclear Materials. 1983;119(23):278-83.

[24] Tzelepi N, Brown M, Matthews PC, Payne JFB, Metcalfe MP. The development of measurement techniques for mechanical properties applicable to small reactor graphite samples. Roy Soc Ch. 2007(309):142-9.

[25] Vasudevamurthy G, Byun TS, Pappano P, Snead LL, Burchell TD. Effect of specimen size and grain orientation on the mechanical and physical properties of NBG-18 nuclear graphite. Journal of Nuclear Materials. 2015;462:1-7.

[26] Standards B. Advanced technical ceramics - Mechanical properties of monolithic ceramics at room temperature - Part 2: Determination of Young's modulus, shear modulus and Poisson's ratio, BS EN 843-2:2006. 2007.

[27] Yoda S, Fujisaki K. An approximate relation between Young's modulus and thermal expansion coefficient for nuclear-grade graphite. Journal of Nuclear Materials. 1983;113(23):263-7.

[28] Massey FJ. The Kolmogorov-Smirnov Test for Goodness of Fit. Journal of the American Statistical Association. 1951;46(253):68-78.

[29] Deb P, Sefton M. The distribution of a Lagrange multiplier test of normality. Economics Letters. 1996;51(2):123-30.

[30] Jarque CM, Bera AK. A Test for Normality of Observations and Regression Residuals. International Statistical Review / Revue Internationale de Statistique. 1987;55(2):163-72.

[31] Conover WJ. Practical nonparametric statistics. 3rd ed. ed. New York

Chichester: New York

Chichester : John Wiley; 1999.

[32] Lilliefors HW. On the Kolmogorov-Smirnov Test for the Exponential Distribution with Mean Unknown. Journal of the American Statistical Association. 1969;64(325):387-9.

[33] Freedman D, Diaconis P. On the histogram as a density estimator:L2 theory. Zeitschrift für Wahrscheinlichkeitstheorie und Verwandte Gebiete. 1981;57(4):453-76.

[34] Brown MB, Forsythe AB. Robust Tests for the Equality of Variances. Journal of the American Statistical Association. 1974;69(346):364-7.

[35] Gibbons JD, Chakraborti S. Nonparametric statistical inference. 5th ed. Boca Raton: Taylor \& Francis; 2011.

[36] Hollander M, Wolfe DA. Nonparametric statistical methods. 2nd ed. New York: Wiley; 1999.

[37] Preston SD, Ellis WE. Techniques for measuring the properties of unirradiated and irradiated AGR graphite. Roy Soc Ch. 2007(309):150-7.

[38] Marlowe MO. Elastic properites of three grades of fine grained graphite to $2000{ }^{\circ} \mathrm{C}$. Pleasanton, California: NASA; 197025 June 1970.

[39] Preston SD. Variation of material properties within a single brick of the Heysham 2/ Torness moderator graphite. Salwick, Preston, UK: Springfields Nuclear Power Development Laboratories; 1988. Report No.: ND-M-3755 (S). 
[40] Brocklehurst JE, Kelly BT. Analysis of the dimensional changes and structural changes in polycrystalline graphite under fast neutron irradiation. Carbon. 1993;31:157-78.

[41] Yoda S, Fujisaki K. Correlation between Some Mechanical and Physical Properties of Polycrystalline Graphites. TANSO. 1982;1982(110):81-8.

[42] Spriggs RM. Expression for Effect of Porosity on Elastic Modulus of Polycrystalline Refractory Materials, Particularly Aluminum Oxide. Journal of the American Ceramic Society. 1961;44(12):628-9.

[43] Knudsen FP. Dependence of Mechanical Strength of Brittle Polycrystalline Specimens on Porosity and Grain Size. Journal of the American Ceramic Society. 1959;42(8):376-87.

[44] ASTM. ASTM D7219-08(2014), Standard Specification for Isotropic and Near-isotropic Nuclear Graphites. West Conshohocken, PA 2014. 